\title{
ANCIENT LAW - UM CLÁSSICO REVISITADO 150 ANOS DEPOIS
}

\author{
ANCIENT LAW - A CLASSIC REVISITED 150 YEARS LATER
}

Orlando Villas Bôas Filho*

\begin{abstract}
Resumo:
Este artigo pretende realçar a importância desempenhada pela obra de Henry James Sumner Maine na formação da antropologia jurídica e da sociologia do direito. Mediante a recuperação da tese central de sua obra Ancient Law, procura ressaltar o papel por ela desempenhado no delineamento de uma nova forma de abordagem da relação entre direito e sociedade. Para tanto, recupera traços gerais das análises de Norbert Rouland e de Niklas Luhmann acerca da importância das ideias do autor.
\end{abstract}

Palavras-chave: Antropologia jurídica. Sociologia do direito. Evolucionismo. Henry James Sumner Maine.

\begin{abstract}
:
This article aims to highlight the importance played by Henry James Sumner Maine in the formation of legal anthropology and sociology of law. To this end, the article reviews the central thesis of his book Ancient Law and seeks to emphasize the importance of his ideas in shaping a new way to approach the relationship between law and society. For this purpose, the article retrieves the general features of the analyses of Norbert Rouland and Niklas Luhmann about the importance of Maine's ideas.
\end{abstract}

Keywords: Anthropology of law. Sociology of law. Evolutionism. Henry James Sumner Maine.

1. Considerações introdutórias

Henry James Sumner Maine (1822-1888) foi professor de Direito Civil da Universidade Cambridge e de Direito Romano em Londres e, a partir de 1869, foi o primeiro professor de direito comparado na Universidade de Oxford. Seus principais livros são Ancient Law (1861), Village-Communities (1871), Lectures on the Early History of Institutions (1875), Dissertations on Early Law and Custom (1883), Popular Government (1885). Dentre essas obras, Ancient Law foi a que recebeu a maior difusão e que gerou maior impacto entre teóricos do direito e, sobretudo, autores da antropologia e da sociologia do direito. Entretanto, apesar da importância histórica de suas ideias e do impacto por elas gerado no delineamento dos contornos originários dos enfoques antropológico e sociológico acerca do direito, a obra de Maine continua a ser negligenciada no Brasil. ${ }^{1}$

\footnotetext{
* Professor Doutor da Faculdade de Direito da Universidade de São Paulo.

1 Para uma análise da vida e obra de Henry James Sumner Maine ver, por exemplo: COCKS, Raymond C. J. Sir Henry Maine: a study in Victorian jurisprudence. Cambridge: Cambridge University Press, 1988, p.
} 
Raymond Cocks ressalta que, mesmo na tradição anglófona, Maine teria sido considerado mais como um jurista do que como um pensador do direito. Partindo dessa constatação, enfatiza a falta de estudos sistemáticos de sua obra, sobretudo no que concerne às suas proposições teóricas acerca do direito. Aliás, conforme Lawrence Rosen, o livro Ancient Law, apesar de sua importância, seria mais citado do que efetivamente lido. ${ }^{2}$ A respeito, Raymond Cocks, corroborando o posicionamento de Frederick Pollock, observa que a razão dessa carência de estudos sistemáticos acerca do pensamento de Maine parece decorrer, em grande medida, do aspecto difuso das ideias do autor. ${ }^{3}$ Por outro lado, sua vinculação a uma perspectiva evolucionista também acarretou limitações à recepção posterior da obra que, de qualquer modo, exerceu significativa influência, sobretudo em autores importantes da teoria do direito anglófona, tais como Oliver Wendell Holmes e Roscoe Pound. ${ }^{4}$

O presente artigo não tem, evidentemente, a pretensão de recuperar em maior minúcia as teses de Maine que, ademais, foram objeto de intensa crítica e não são mais passíveis de aceitação. ${ }^{5}$ Seu objetivo consiste em aquilatar o papel histórico de sua obra sem, com isso, aderir ou corroborar suas teses. Nesse sentido, será feito um breve exame da mais influente proposição sustentada por Maine em seu livro Ancient Law, qual seja: a de que as instituições jurídicas se desenvolveriam passando do status ao contrato. Para tanto, a análise estará articulada basicamente ao redor da hipótese relativa à evolução do direito, proposta por Maine após sua critica ao que ele denomina conjectural theories. Em seguida, procurar-se-á indicar a importância de sua obra para a formação

1-12; ROSEN, Lawrence. Foreword. In: MAINE, Henry James Sumner. Ancient Law, its Connection with the Early History of Society, and its Relation to Modern Ideas. Tucson, Arizona: The University of Arizona Press, 1986, p.vii-xx.

2 Cf. ROSEN, Lawrence. Foreword, p. vii. Isso se observa, por exemplo, no livro de Robert Weaver Shirley, uma das mais difundidas obras de antropologia jurídica no ensino universitário brasileiro. Cf. SHIRLEY, Robert Weaver. Antropologia jurídica. São Paulo: Saraiva, 1987, p. 21.

3 Apesar dessa carência de estudos, Raymond Cocks sublinha a importância de três obras que analisam o pensamento de Maine: Peter G. Stein (Legal evolution: the story of an Idea, 1980), John W. Burrow (Evolution and society, 1966) e George Feaver (From status to contract, 1969). Cf. COCKS, Raymond C. J. Sir Henry Maine: a study in Victorian jurisprudence, p. 8-9. A respeito, cabe também indicar a excelente coletânea de artigos editada por Alan Diamond na qual, além de artigos dos já aludidos George Feaver, John Burrow, Peter Stein e Raymond Cocks, se encontram também análises de John Lyons e Adam Kuper acerca do pensamento de Maine. Cf. DIAMOND, Alan (Ed.). The victorian achievement of Sir Henry Maine: a centennial reappraisal. New York: Cambridge University Press, 1991. A respeito, ver também: POLLOCK, Frederick. Introduction and notes to Sir Henry Sumner Maine's "Ancient Law". London: John Murray, 1914.

4 Cf. ROSEN, Lawrence. Foreword, p. xvii.

5 Nesse particular é bem elucidativa a observação de Henry Orenstein acerca do caráter ideológico da teoria de Maine. Orenstein procura ressaltar o déficit de sistematicidade do pensamento de Maine, enfatizando que seu propósito consistiria em "try to show that the different aspects of his theory were, in fact, related, but that this relationship is not so much a scientific or logical one as one more plausibly to be comprehended in the context of the general socio-political ideas and issues current in his time. That is, his substantive theory was part or ideological [...]" ORENSTEIN, Henry. The ethnological theories of Henry Sumner Maine. In: American Anthropologist, 70, 1968, p. 264. 
da abordagem antropológica e da sociológica acerca do direito no contexto da segunda metade do século XIX.

\section{Ancient Law}

Seguindo Norbert Rouland, é possível afirmar que a obra Ancient Law de Maine seria atravessada por duas teses centrais. Em primeiro lugar, estaria a teoria dos estágios de desenvolvimento do direito. Em segundo lugar, estaria a tentativa de estabelecer a anterioridade da descendência patrilinear e da sociedade patriarcal. ${ }^{6} \mathrm{~A}$ presente análise ficará centrada basicamente na teoria dos estágios de desenvolvimento, no bojo da qual é proposta a ideia da evolução do direito. John Kelly sintetiza bem a tese de Maine, ressaltando, sobretudo, que:

baseando suas teorias num certo conhecimento de direito romano, grego e bíblico e de outros sistemas antigos de direito (inclusive as leis da antiga Irlanda), bem como nas instituições nativas da Índia daquela época, ele apresentou, primeiro, a noção de que as sociedades de todos os tipos tendem a se desenvolver, no que diz respeito a sua vida jurídica, passando por certas fases que são as mesmas em toda parte. Ele achava que a primeira fase - a que se manifesta nos poemas homéricos - era em certo sentido pré-jurídica: os reis proferiam julgamentos sobre disputas concretas, e um elemento de inspiração divina, ou de mediação de julgamentos de ordem divina, ligavase a esses thémistes isolados, ou dooms (sentenças - o equivalente germânico). ${ }^{7} \mathrm{~A}$ fase seguinte, provavelmente

6 Cf. ROULAND, Norbert. Anthropologie juridique. Paris: Presses Universitaires de France, 1988, p. 50. A respeito da segunda tese, Malinowski enfatizava que o pensamento de Maine seria „handicapped by his too narrow adhesion to the patriarchal scheme." MALINOWSKI, Bronislaw. Crime and Custom in Savage Society. $7^{\text {th }}$ Ed. London: Routledge \& Kegan Paul Ltd., 1961, p. 3.

7 Conforme enfatiza Maine, "the earliest notions connected with the conception, now so fully developed, of a law or rule of life, are those contained in the Homeric words 'Themis' and 'Themistes'. 'Themis', it is well known, appears in the later Greek pantheon as the Goddess of Justice, but this is a modern and much developed idea, and it is in a very different sense that 'Themis' is described in the Iliad as the assessor of Zeus. It is now clearly seen by all trustworthy observer of the primitive condition of mankind that, in the infancy of the race, men could only account for sustained or periodically recurring action by supposing a personal agent. Thus, the wind blowing was a person and of course a divine person; the sun rising, culminating, and setting was a person and a divine person; the earth yielding her increase was a person and divine. As, then, in the physical world, so in the moral. When a king decided a dispute by a sentence, the judgment was assumed to be the result of direct inspiration. The divine agent, suggesting judicial awards to kings or to gods, the greatest of kings, was Themis. The peculiarity of the conception is brought out by the use of the plural. Themistes, Themises, the plural of Themis, are the awards themselves, divinely dictated to the judge. Kings are spoken of as if they had a store of 'Themistes' ready to hand for use; but it must be distinctly understood that they are not laws, but judgments." MAINE, Henry James Sumner. Ancient Law, its Connection with the Early History of Society, and its Relation to Modern Ideas. Tucson, Arizona: The University of Arizona Press, 1986, p. 3-4. Para explicações acerca do conceito de Themistes, ver, por exemplo: PEÑA, Guillermo de la. Costumbre, ley y procesos judiciales en la antropología clásica: apuntes 
possibilitada pela repetição e padronização dos julgamentos, foi a consolidação de um costume do qual eram guardiãs as oligarquias que sucederam a realeza [...]. A terceira fase, associada com um movimento mais ou menos democrático para quebrar o monopólio oligárquico da jurisdição, é dos códigos (da qual realmente a Grécia oferece vários exemplos, aproximadamente na mesma época das Doze Tábuas de Roma). Nesse ponto, algumas sociedades param de se desenvolver; suas instituições jurídicas nunca adquirem novas dimensões além de seu código petrificado: a essas sociedades Maine chama de 'estáticas'. Outras sociedades, contudo, tinham a habilidade de adaptar suas leis às novas circunstâncias; essas, as sociedades 'dinâmicas', ele achava que tendiam a empregar três mecanismos de mudança: ficções jurídicas, equidade e legislação. ${ }^{8}$

Nota-se, assim, que ao desenvolver sua teoria dos três estágios de desenvolvimento do direito, Maine ressalta que, num primeiro estágio, teria sido atribuída uma fonte divina ao direito. Em seguida, no segundo estágio, teria havido a identificação do direito com o costume. Por fim, no terceiro estágio, o direito seria identificado com a lei posta por uma autoridade. O que importa observar é que, segundo Maine, no âmbito de seu processo de evolução, o direito teria passado "do status ao contrato." Conforme enfatizam vários comentadores, trata-se, indiscutivelmente, da tese mais importante do autor. $^{10}$

introductorios. In: KROTZ, Esteban. (Ed.) Antropología jurídica: perspectivas socioculturales en el estudio del derecho. Rubí (Barcelona): Anthropos Editorial; México: Universidad Autónoma Metropolitana - Iztapalapa, 2002, p. 53; ORENSTEIN, Henry. The ethnological theories of Henry Sumner Maine. In: American Anthropologist, 70, p. 264-276, 1968.

8 KELLY, John Maurice. Uma breve história da teoria do direito ocidental. Tradução de Marylene Pinto Michael. São Paulo: Martins Fontes, 2010, p. 430-431. No mesmo sentido, ver: PEÑA, Guillermo de la. Costumbre, ley y procesos judiciales en la antropología clásica: apuntes introductorios, p. 52-55. Sobre a influência do antigo direito romano para alguns dos "pais fundadores" da sociologia jurídica, dentre os quais Maine, ver: PÖLÖNEN, Janne. The case for a Sociology of Roman Law. In: FREEMAN, Michael (Ed.). Law and sociology: current legal issues vol. 8. Oxford: Oxford University Press, 2005, p. 398-408.

9 A tese aparece textualmente expressa nos seguintes termos: "the movement of the progressive societies has hitherto been a movement from status to contract." MAINE, Henry James Sumner. Ancient Law, its Connection with the Early History of Society, and its Relation to Modern Ideas, p. 165.

10 A. Javier Treviño, por exemplo, afirma que "undoubtedly, Maine's most enduring contribution to the sociology of law is his proposal that societies undergo a transition from status to contract. In his view, this social evolution involves a move from giving legal emphasis to the individual's rights and duties based on status, or the social position derived from family relations, to giving legal emphasis to the individual's rights and duties based on contract, or those personal bargains resulting from individual will.” TREVIÑO, A. Javier. The sociology of law: classical and contemporary perspectives. New Jersey: Transaction Publishers, 2008, p. 21. A respeito, ver também: CARBONNIER, Jean. Sociologie juridique. 2e édition. Paris: Presses Universitaires de France, 2008, p. 89; HOEBEL, Edward Adamson. The law of primitive man: a study in comparative legal dynamics. Cambridge, Massachusetts: Harvard University Press, 2006, p. 327-328. 
Entretanto, a compreensão da tese de Maine implica a elucidação do que o autor entende por status e por contrato. A esse respeito, Niklas Luhmann esclarece que, na obra Ancient Law, os conceitos de status e de contrato não são expressão de institutos jurídicos exclusivamente lógicos, mas sim de princípios básicos da construção da ordem jurídica e da distribuição de direitos e deveres que devem ser considerados à luz das estruturas sociais que lhes dão esteio. ${ }^{11}$ Nesse sentido, segundo Maine, nas "sociedades primitivas", os direitos e obrigações dos indivíduos seriam fixados de forma rígida pelo seu status, ao passo que, posteriormente, como decorrência do crescimento da mobilidade social dos diversos grupos, os direitos e obrigações passariam a ser determinados pelo princípio do contrato.

Assim, para Maine, no direito das "sociedades primitivas" (society in primitive times), os indivíduos estariam submersos no grupo, ou seja, não seria possível afirmar a existência de indivíduos isolados, como a unidade básica da vida social, previamente à constituição do grupo ao qual integram. ${ }^{12}$ Como decorrência dessa dissolução do indivíduo no grupo, não haveria nas "sociedades primitivas" o correlato do que se entende modernamente por direitos e obrigações individuais. ${ }^{13} \mathrm{O}$ "direito primitivo" (primitive law) se estruturava visando ajustar-se a um sistema de pequenas corporações independentes de modo que as transações jurídicas seriam entabuladas a partir da relação entre tais corporações e não mediante o intercurso entre indivíduos. ${ }^{14} \mathrm{O}$ próprio crime não consistiria numa ação individual e sim num evento coletivo (crime is a corporate act). ${ }^{15}$ Entretanto, a esse respeito, Guillermo de la Peña observa que a obra de Maine também consignava uma preocupação concernente às relações entre indivíduo e grupo e às condições por intermédio das quais os indivíduos poderiam se tornar sujeitos de direito. ${ }^{16}$

Opondo-se a teorias como as de Thomas Hobbes e de John Locke, Maine critica a concepção do homem como um ser racional e livre, considerado individualmente

11 Cf. LUHMANN, Niklas. Rechtssoziologie. 4. Aufl. Wiesbaden: VS Verlag für Sozialwissenschaften, 2008, p. 14.

12 Cf. MAINE, Henry James Sumner. Ancient Law, its Connection with the Early History of Society, and its Relation to Modern Ideas, p. 121.

13 Henry Orenstein sintetiza bem esse aspecto ao afirmar que "Maine believed that the social condition of the individual in ancient times can best be conceived as a university of rights acquired solely through family membership. In a word, it was a status." ORENSTEIN, Henry. The ethnological theories of Henry Sumner Maine, p. 265.

14 Cf. MAINE, Henry James Sumner. Ancient Law, its Connection with the Early History of Society, and its Relation to Modern Ideas, p. 121

15 Conforme ressalta Maine, "If the community sins, its guilt is much more than the sum of the offences committed by its members; the crime is a corporate act, and extends in its consequences to many more persons than have shared in its actual perpetration." MAINE, Henry James Sumner. Ancient Law, its Connection with the Early History of Society, and its Relation to Modern Ideas, p. 122.

16 Cf. PEÑA, Guillermo de la. Costumbre, ley y procesos judiciales en la antropología clásica: apuntes introductorios, p. 56 
no estado de natureza, pois, segundo ele, essa concepção não seria verossímil, fundando-se, ao contrário, em bases especulativas (speculative basis). Para ele, as teorias de Hobbes e de Locke, apesar das dissensões por elas engendradas no pensamento político, partilhariam as mesmas premissas conjecturais, inverificáveis e desprovidas de embasamento histórico. ${ }^{17}$ Para Maine, o homem não poderia ser concebido como naturalmente racional e tomado a partir de sua individualidade, uma vez que, no que concerne a esse segundo aspecto, ele já se encontraria originalmente inserido em famílias (donde, aliás, decorreria sua completa subordinação ao poder paternal). ${ }^{18}$ Ademais, ao contrário da concepção hobbesiana, para Maine, o homem seria sociável e, mesmo antes da instituição do poder civil, estaria colocado em formas concretas de organização tais como a família. Assim, numa posição que o insere claramente no âmbito das teorias que encontram nas relações de parentesco o fundamento da ordem social, ${ }^{19}$ Maine afirma que:

17 Cf. MAINE, Henry James Sumner. Ancient Law, its Connection with the Early History of Society, and its Relation to Modern Ideas, p. 110. No que concerne especificamente à tese hobbesiana, Maine afirma que "Hobbes, it is well known, speculated on the origin of Government and Sovereignty. [...] It is true that nothing can be more worthless in itself than Hobbes's conjectural account of the origin of society and government." Cf. MAINE, Henry James Sumner. Lectures on the Early History of Institutions. $6^{\text {th }}$ ed. London: John Murray, 1898 , p. 356. Não é possível recompor aqui a tese hobbesiana para um contraponto mais detido. Nesse particular, remeto o leitor, sobretudo, aos capítulos XIII, XIV e XV do Leviatã. Acerca da perspectiva de Hobbes no que concerne ao homem em estado de natureza, ver, por exemplo: TUCK, Richard. Natural rights theories: their origin and development. Cambridge: Cambridge University Press, 1995, p. 120-125; ZAGORIN, Perez. Hobbes and the Law of Nature. Princeton, New Jersey: Princeton University Press, 2009, p. 32 e ss; WEINREB, Lloyd L. Natural Law and Justice. Cambridge, Massachusetts: Harvard University Press, 1987, p. 68-76. A bibliografia sobre a obra de Hobbes é imensa. Por esse motivo, não há como recompor um inventário minimamente razoável das obras importantes que analisam seu pensamento. No contexto brasileiro são incontornáveis as obras de Renato Janine Ribeiro. A respeito, ver especialmente: RIBEIRO, Renato Janine. Ao leitor sem medo: Hobbes escrevendo contra o seu tempo. Belo Horizonte: Editora da UFMG, 1999, p. 79-114; 177-207. Dentre as análises de juristas acerca de Hobbes que se afiguram como influentes no Brasil, cabe indicar, a guisa de mera ilustração, as seguintes obras: BOBBIO, Norberto. Thomas Hobbes. Tradução de Carlos Nélson Coutinho. Rio de Janeiro: Campus, 1991; FERRAZ JUNIOR, Tercio Sampaio. Estudos e filosofia do direito: reflexões sobre o poder, a liberdade, a justiça e o direito. $3^{\mathrm{a}}$ ed. São Paulo: Atlas, 2009, p. 87-93; LAFER, Celso. Hobbes, o direito e o Estado moderno. São Paulo: Associação dos Advogados de São Paulo, 1980; VILLEY, Michel. A formação do pensamento jurídico moderno. Tradução de Cláudia Berliner. São Paulo: Martins Fontes, 2009, p. 674-755.

18 Segundo Orenstein, "Maine did not believe that man was naturally 'rational'; modern 'progressive' institutions are not attributable to the calculated efforts of men to increase their satisfactions. They arose in large part from a base of 'murky superstition. [...] Hence, Maine saw primitive man, within family, entirely subject to paternal power, which derived whatever regularity it possessed from semiconscious adherence to custom." ORENSTEIN, Henry. The ethnological theories of Henry Sumner Maine, p. 268. Evidencia-se, assim, a distância que Maine mantém daquilo que Crawford Brough Macpherson denominou de "teoria política do individualismo possessivo". Para uma descrição dos elementos constitutivos do "individualismo possessivo", ver: MACPHERSON, Crawford Brough. The political theory of possessive individualism: Hobbes to Locke. Don Mills, Ont.; Oxford: Oxford University Press Canada, 2011, p. 263 e ss.

19 Conforme enfatizam Edwige Rude-Antoine e Geneviève Chrétien-Vernicos, a noção de parentesco constitui um dos domínios mais importantes do desenvolvimento teórico da antropologia. As autoras remetem para uma afirmação de R. Fox, para quem "la parenté est à l'anthropologie ce que la logique est à la philosophie et l'étude du nu aux arts plastiques: la discipline de base." RUDE-ANTOINE, 
It is full, in all its provinces, of the clearest indications that society in primitive times was not what it is assumed to be at present, a collection of individuals. In fact, and in the view of the men who composed it, it was an aggregation of families. The contrast may be most forcibly expressed by saying that the unit of an ancient society was the Family, of a modern society the Individual. ${ }^{20}$

Nota-se, assim, que a perspectiva de Maine está nas antípodas daquilo que Crawford B. Macpherson denominou de "teoria política do individualismo possessivo", na qual, como bem observa Richard Tuck, o homem é pressuposto como proprietário (owner) de sua liberdade e de outros atributos morais. ${ }^{21}$ Essa teoria que, segundo Macpherson, encontra sua sistematização fundamental, no século XVII, nos pensamentos de Thomas Hobbes e de John Locke, ${ }^{22}$ parte de uma concepção de homem que é completamente rejeitada pela perspectiva de Maine. ${ }^{23} \mathrm{O}$ modo pelo qual o homem aparece descrito, em estado de natureza, nas obras de Thomas Hobbes e John Locke, seria, para Maine, expressão de mera conjectura. Segundo ele, "these two theories, which long divided the reflecting politicians of England into hostile camps, resemble each other strictly in their fundamental assumption of a nonhistoric, unverifiable, condition of the race." 24

Segundo Maine, o homem "selvagem" não teria regras nem limitações ou capacidade de acordo racional. Por essa razão, a figura do contrato somente

Edwige; CHRÉTIEN-VERNICOS, Geneviève. Parenté, famille, mariage, filiation. In: (Coord.). Anthropologies et droits: état des savoirs et orientations contemporaines. Paris: Dalloz, 2009, p. 275.

20 MAINE, Henry James Sumner. Ancient Law, its Connection with the Early History of Society, and its Relation to Modern Ideas, p. 121. Essa questão é especialmente tratada no terceiro capítulo do livro Lectures on the early history of institutions, no qual Maine analisa as relações de parentesco como base da sociedade. Cf. MAINE, Henry James Sumner. Lectures on the Early History of Institutions, p. $64-$ 97. Para uma crítica à influente tese de que as sociedades "primitivas" seriam kin-based societies, ou seja, de que estariam fundadas em relações de parentesco, ver: GODELIER, Maurice. Au fondement des sociétés humaines: ce que nous apprend l'anthropologie. Paris: Albin Michel, 2007, p. 54; Communauté, société, culture: trois clefs pour comprendre les identités en conflits. Paris: CNRS Éditions, 2009, p. 14-16; . Les tribus dans l'histoire et face aux États. Paris: CNRS Éditions, 2010, p. 11-23. Para uma discussão acerca do enquadramento de Maine nessa perspectiva teórica, ver: SHILS Edward. Henry Sumner Maine in the tradition of the analysis of society. In: DIAMOND, Alan (Ed.). The victorian achievement of Sir Henry Maine: a centennial reappraisal. New York: Cambridge University Press, 1991, p. 140-141.

21 Cf. TUCK, Richard. Natural rights theories: their origin and development, p. 3.

22 Cf. MACPHERSON, Crawford Brough. The political theory of possessive individualism: Hobbes to Locke, p. 3-4. Para uma crítica à tese de Macpherson, ver: TUCK, Richard. Natural rights theories: their origin and development, p. 2-3.

23 A esse respeito, Maine enfatiza que "society in primitive times was not what it is assumed to be at present, a collection of individuals. In fact, and in the view of the men who composed it, it was an aggregation of families." MAINE, Henry James Sumner. Ancient Law, its Connection with the Early History of Society, and its Relation to Modern Ideas, p. 121.

24 MAINE, Henry James Sumner. Ancient Law, its Connection with the Early History of Society, and its Relation to Modern Ideas, p. 110. 
surgiria na história humana recente. Conforme sustenta o autor, na sociedade patriarcal, o indivíduo estaria totalmente integrado à família e submetido ao poder paternal, motivo pelo qual o direito se confundiria com o costume. ${ }^{25}$ Por isso, o advento do contrato como forma de ordenação é por ele considerado como um ganho evolutivo. Desse modo, o processo de organização das sociedades se iniciaria com o status, fundado no laço de parentesco, e se concluiria com o contrato, concebido como expressão da racionalidade e como fruto da evolução social. ${ }^{26}$ Assim, Maine ressalta que:

the movement of the progressive societies has been uniform in one respect. Through all its course it has been distinguished by the gradual dissolution of family dependency and de growth of individual obligation in its place. The Individual is steadily substituted for the Family, as the unity of which civil law take accounts. ${ }^{27}$

Conforme enfatiza Niklas Luhmann, na concepção de Maine, em sociedades baseadas no princípio do parentesco e divididas em famílias e linhagens, a participação no direito ficaria condicionada à inclusão nessas sociedades e ao grau de inserção em termos de status. Nesse sentido, seria o status que conferiria a capacidade jurídica, o que implica afirmar que tal capacidade não é generalizada e sim atribuída de forma diferenciada e concreta. Entretanto, paulatinamente, o desenvolvimento social engendraria um implemento de complexidade (decorrente, sobretudo, do aumento do volume quantitativo e das interdependências econômicas) que forçaria uma maior mobilização das relações jurídicas, levando à dissolução de formas convencionais demasiadamente compactas, transmitidas por tradição, com validade apenas local e dependentes de condições sócio-estruturais que lhes seriam determinantes. ${ }^{28} \mathrm{Com}$ isso, a dominação política desvincular-se-ia das antigas ordens familiares e de linhagem permitindo, assim, a concessão de um maior grau de liberdade e mobilidade aos indivíduos.

25 A esse respeito, Orenstein ressalta que "Maine saw primitive man, within his family, entirely subject to paternal power, which derived whatever regularity it possessed from semiconscious adherence to custom." ORENSTEIN, Henry. The ethnological theories of Henry Sumner Maine, p. 268.

26 A respeito, Norbert Rouland $(1995$, p. 23) ressalta que "pour les auteurs évolutionnistes (notamment H. Sumner-Maine), l'évolution se traduit par le passage du status au contrat, caractéristique des sociétés modernes, alors que dans les sociétés traditionnelles, ce ne serait pas l'accord des volontés individuelles mais le status d'une personne au sein de la société qui engendrait ses obligations, privilèges et responsabilités." No mesmo sentido, ver: ORENSTEIN, Henry. The ethnological theories of Henry Sumner Maine, p. 270. Conforme bem o nota Jean Carbonnier, para Maine, "le status est compris comme la famille patriarcale [...]. CARBONNIER, Jean. Sociologie juridique, p. 246.

27 MAINE, Henry James Sumner. Ancient Law, its Connection with the Early History of Society, and its Relation to Modern Ideas, p. 163.

28 Cf. LUHMANN, Niklas. Rechtssoziologie, p. 14 e 308-309; Ausdifferenzierung des Rechts. Beiträge zur Rechtssoziologie und Rechtstheorie. Frankfurt am Main: Suhrkamp, 1999, p. 301. 
Desse modo, no final do século XVIII, com a dissolução da ordem estamental, o homem, tomado a partir de sua personalidade abstrata, tornar-se-ia detentor do direito não em virtude de sua posição na estrutura social, ou seja, em razão de seu status. Com a dissolução dessa forma demasiadamente concreta de distribuição de direitos e de obrigações, um novo instrumento distributivo de direitos e obrigações passaria a se impor: o contrato. Referindo-se a esse processo, Maine ressalta que "nor is it difficult to see what is the tie between man and man which replaces by degrees those forms of reciprocity in rights and duties which have their origin in the Family. It is Contract." 29

Cabe ainda ressaltar que Maine, um século antes de Herbert Hart, já criticava as perspectivas de Jeremy Bentham e de John Austin. ${ }^{30}$ Sua crítica enfatiza justamente a redução do direito ao comando estabelecido por uma autoridade soberana, aspecto esse que, como se sabe, constitui o objeto central da crítica que Hart endereça à teoria imperativista. ${ }^{31}$ Não cabe aqui reproduzir a objeção que Hart endereça ao pensamento de Austin e Bentham, pois o que se visa é apenas indicar que o teor geral da mesma já aparece explicitado, ainda que a partir de outras premissas e visando outros propósitos, no pensamento de Maine. Para tanto, basta notar que o ponto essencial da crítica de Hart à teoria imperativista consiste em apontar a redução do direito à simples noção de uma "ordem baseada em ameaças" que, seguindo a denominação de Austin, poderia ser designada de "comando". ${ }^{32}$ Ora, o contorno geral dessa crítica já

29 MAINE, Henry James Sumner. Ancient Law, its Connection with the Early History of Society, and its Relation to Modern Ideas, p. 163. Luhmann enfatiza justamente esse ponto no pensamento de Maine ao afirmar que, no bojo do processo de evolução social, "das neue Verteilungsmittel heißt Vertrag." LUHMANN, Niklas. Rechtssoziologie, p. 15. A respeito, ver também: SUPIOT, Alain. Homo juridicus. Essai sur la fonction anthropologique du droit. Paris: Éditions du Seuil, 2005, p. 136.

30 Para uma extensa análise acerca da questão da soberania nos pensamentos de Austin e Bentham, inclusive numa relação com a teoria de Hobbes, ver: MAINE, Henry James Sumner. Lectures on the Early History of Institutions, p. 342 e ss. Para uma análise dos pensamentos de Austin e de Bentham que os relaciona com a origem do positivismo jurídico na Inglaterra, ver: BOBBIO, Norberto. O positivismo jurídico: lições de filosofia do direito. Tradução de e notas Márcio Pugliesi, Edson Bini, Carlos E. Rodrigues. São Paulo: Ícone, 1995, p. 91-118. Para uma análise introdutória ao pensamento de Austin, ver, por exemplo: SGARBI, Adrian. Clássicos da teoria do direito. $2^{\mathrm{a}}$ ed. Rio de Janeiro: Lumen Juris, 2009, p. 1-29; OPPETIT, Bruno. Philosophie du droit. Paris: Dalloz, 1999, p. 60.

31 Cf. HART, Herbert L. A. O conceito de direito. Tradução de Armindo Ribeiro Mendes. Lisboa: Fundação Calouste Gulbenkian, 1986, p. 21-31. Acerca da caracterização dada por Austin ao direito, ver, sobretudo: AUSTIN, John. The province of jurisprudence determined. Cambridge: Cambridge University Press, 2001, p. 18-37; 164-293.

32 Cf. HART, Herbert L. A. O conceito de direito, p. 21. A respeito, ver, por exemplo: HÖFFE, Otfried. Justiça política: fundamentação e uma filosofia crítica do direito e do Estado. Tradução de Ernildo Stein. Petrópolis, RJ: Vozes, 1991, p. 134-141; MILLARD, Éric. Théorie générale du droit. Paris: Dalloz, 2006, p. 81-84; SÈVE, René. Philosophie et théorie du droit. Paris: Dalloz, 2007, p. 131-135; SGARBI, Adrian. Clássicos da teoria do direito, p. 103-128; TROPER, Michel. Le droit et la nécessité. Paris: Presses Universitaires de France, 2011, p. 91; GRZEGORCZYK, Christophe; MICHAUT, Françoise; TROPER, Michel. Le positivisme juridique. Paris: L.G.D.J, 1992, p. 41-45. 
está expresso em Ancient Law. Referindo-se às teorias de Austin e Bentham, Maine enfatiza que:

Bentham, in his 'Fragment on Government', and Austin, in his 'Province of Jurisprudence Determined', resolve every law into a command of the lawgiver, an obligation imposed thereby on the citizen, and a sanction threatened in the event of disobedience; and it is further predicated of the command, which is the first element in a law, that it must prescribe, not a single act, but a series or number of acts of the same class or kind. The results of this separation of ingredients tally exactly with the facts of mature jurisprudence; and, by a little straining of language, they may be made to correspond in form with all law, of all kinds, at all epochs. It is not, however, asserted that the notion of law entertained by the generality is even now quite in conformity with this dissection; and it is curious that, the farther we penetrate into the primitive history of thought, the farther we find ourselves from a conception of law which at all resembles a compound of the elements which Bentham determined. It is certain that, in the infancy of mankind, no sort of legislature, not even a distinct author of law, is contemplated or conceived of. Law has scarcely reached the footing of custom; it is rather a habit. ${ }^{33}$

O trecho reproduzido acima permite observar que Maine - procurando descrever o desenvolvimento do direito ao longo da história, de modo a fundamentar sua tese - propugna restrições semelhantes às de Hart ao pensamento de Austin e ao de Bentham. Maine, aliás, ressalta que a redução do direito ao "comando" simplesmente escamotearia questões fundamentais acerca da evolução histórica do direito que, segundo ele, precisariam ser elucidadas. Nesse sentido, ressalta que:

The resolution of a law into a command of a particular nature, imposed under special conditions, does not affect to do more than protect us against a difficulty - a most formidable one certainly - of language. The whole question remains open as to the motives of societies in imposing these commands on themselves, as to the connexion of these commands with each other, and the nature of their dependence on those which preceded them, and which they have superseded. ${ }^{34}$

\footnotetext{
33 MAINE, Henry James Sumner. Ancient Law, its Connection with the Early History of Society, and its Relation to Modern Ideas, p. 6-7.

34 MAINE, Henry James Sumner. Ancient Law, its Connection with the Early History of Society, and its Relation to Modern Ideas, p. 113.
} 
A obra Ancient Law já consigna, portanto, aspectos fundamentais que atravessarão, um século mais tarde, a célebre crítica endereçada por Hart ao "imperativismo", fato esse que, entretanto, é sistematicamente menosprezado. Aliás, a esse respeito, cabe notar que, conforme enfatizava Maine, para os teóricos ingleses, seria mais evidente que para aqueles que se inserem em outras tradições o fato histórico que de que a noção de Themistes, tal como ele a define, teria precedido toda e qualquer conceituação acerca do direito. ${ }^{35}$ Nesse contexto, a crítica dirigida por Hart ao "imperativismo" de Austin não seria nada surpreendente se tomada à luz da tradição britânica. ${ }^{36}$ A respeito, Neil MacCormick enfatiza que a Teoria Geral do Direito estava estagnada na Inglaterra à época em que Hart começou a desenvolver sua obra. Segundo ele, "dois grandes movimentos do pensamento o século XIX estavam agonizantes. De um lado, havia uma tradição de Teoria Analítica do Direito, benthamita em inspiração intelectual, mas baseada diretamente em Province of Jurisprudence Determined [...] de John Austin. Do outro lado, havia a Escola Histórica o Direito, que partia de Ancient Law [...] de Sir Henry Maine, até certo ponto uma reação contra a teoria austiniana." 37 Entretanto, diante dessas duas vertentes agonizantes, Hart, no livro The Concept of $L a w$, não dispensa atenção à obra e Maine que, conforme indicado por MacCormick, já expressava uma reação à teoria de Austin.

\section{Entre Antropologia Jurídica e Sociologia do Direito ${ }^{38}$}

A obra de Henry James Sumner Maine é reivindicada tanto pelos sociólogos como pelos antropólogos do direito. Norbert Rouland, por exemplo, considera que a

35 Aliás, Maine enfatiza que "the 'Themistes' have too, it should be remarked, the characteristic which, in the view of Bentham and Austin, distinguishes single or mere commands from laws." MAINE, Henry James Sumner. Ancient Law, its Connection with the Early History of Society, and its Relation to Modern Ideas, $\mathrm{p}$. 8.

36 Para uma análise acerca da especificidade do sistema da Common Law e das abordagens teóricas a ele referidas, ver: WOODMAN, Gordon R. The involvement of English Common Law with other Laws. In: EBERHARD, Christoph; VERNICOS, Geneviève (Eds.). La quête anthropologique du droit: autour de la demarche d'Étienne le Roy. Paris: Karthala, 2006, p. 477-500.

37 MACCORMICK, Neil. H. L. A. Hart. Tradução de Cláudia Santana Martins. Rio de Janeiro: Elsevier, 2010, p. 32 .

38 No que concerne aos termos "antropologia jurídica" e "sociologia do direito" é necessário fazer algumas observações. Há todo um debate acerca da melhor maneira de se designar a abordagem antropológica acerca do direito. Conforme ressaltam Edwige Rude-Antoine e Geneviève Chrétien-Vernicos, "A expressão "antropologia jurídica" teria por finalidade delimitar, por razões essencialmente didáticas, o campo particular de estudo de uma disciplina que, tal como a antropologia, é essencialmente holística. Nesse sentido, o qualificativo "jurídico", justaposto ao enfoque antropológico, permitiria a definição dos fenômenos por ele qualificados como pertencentes ao campo do direito. Assim, a "antropologia jurídica" não se confundiria com a "antropologia do direito", concebida em termos de uma etapa essencial no processo de desfiliação (désaffiliation) da pesquisa antropológica em relação às "ciências jurídicas" e, portanto, de negação de uma atitude ancilar que a tornava uma espécie de "satélite" de uma ciência principal denominada genericamente "direito" (le Droit). Por outro lado, o uso do 
antropologia jurídica somente teria tido início, em 1861, com a publicação de seu livro Ancient Law e da obra Das Mutterrecht de Johann Jakob Bachofen. ${ }^{39}$ Por outro lado, Niklas Luhmann insere a obra de Maine dentre aquelas que comporiam o que ele denomina de "abordagens clássicas da sociologia do direito". ${ }^{40}$ Para os propósitos deste artigo serão recuperados os traços gerais das análises propostas por Rouland e por Luhmann como forma de ilustrar as características de duas novas abordagens acerca da relação entre direito e sociedade (antropologia e sociologia), surgidas no século XIX, para as quais a obra de Maine constitui uma importante contribuição.

A abordagem antropológica e a sociológica do direito surgem, ambas, no século XIX, direcionando-se, num primeiro momento, respectivamente, às sociedades ditas "exóticas" e às sociedades ocidentais modernas. ${ }^{41}$ Essa clivagem evidentemente se perdeu posteriormente. A antropologia não está mais adstrita ao estudo do que, no jargão do século XIX, se convencionou denominar de "povos primitivos". Ao contrário, o que se observa é uma crescente justaposição dos campos de análise da antropologia e da sociologia. Nesse sentido, conforme Michel Alliot, o que define hoje a antropologia jurídica não é um domínio exclusivo de análise e sim um método de abordagem. ${ }^{42}$ Seja como for, em termos históricos, Louis Assier-Andrieu ressalta

sintagma "antropologia da juridicidade", em razão de sua maior amplitude, serviria para qualificar a abordagem dos fenômenos de regulação que são tidos pelos membros das diversas sociedades como obrigatórios e, justamente por isso, sancionados, logo jurídicos. Nesse sentido, essa expressão pretenderia estar mais desatrelada das representações ocidentais acerca do fenômeno jurídico, aceitando como direito tanto as práticas de regulação mais próximas da tradição ocidental moderna como aquelas que são mais distantes." Cf. RUDE-ANTOINE, Edwige; CHRÉTIEN-VERNICOS, Geneviève. (Coord.). Anthropologies et droits: état des savoirs et orientations contemporaines, p. 6. Será utilizado aqui o termo "antropologia jurídica" em função se sua maior recorrência. No que concerne à expressão "sociologia do direito", não se utiliza aqui à distinção feita por Roberto Lyra Filho entre "sociologia jurídica", entendida enquanto "exame do direito em geral", e "sociologia do direito", entendida como estudo da "base social de um direito específico", pois em diversas tradições os termos Rechtssoziologie, Sociologie du droit e Sociology of law assumem justamente o sentido de abordagens gerais acerca do direito. Acerca da distinção proposta por Roberto Lyra Filho, ver: FARIA, José Eduardo; CAMPILONGO, Celso Fernandes. A sociologia jurídica no Brasil. Porto Alegre: Sergio Antonio Fabris Editor, 1991, p. 27, nota 11.

39 Cf. ROULAND, Norbert. Anthropologie juridique, p. 49.

40 Cf. LUHMANN, Niklas. Rechtssoziologie, p. 12. No mesmo sentido, Renato Treves insere o pensamento de Maine no bojo de sua análise acerca da sociologia do direito de Herbert Spencer. Nesse sentido, ver: TREVES, Renato. Sociologia do direito: origens, pesquisas e problemas. Tradução de Marcelo Branchini. Barueri,SP: Manole, 2004, p. 45-46. Para uma análise que se desenvolve de forma semelhante, ver: ROULAND, Norbert. Anthropologie juridique, p. 55-56.

${ }^{41}$ Cf. ROULAND, Norbert. L'anthropologie juridique, p. 12-14; L'ESTOILE, Benoît de; NEIBURG, Federico; SIGAUD, Lygia. Antropologia, impérios e estados nacionais: uma abordagem comparativa. In:

L'ESTOILE, Benoît de; NEIBURG, Federico; SIGAUD, Lygia. (orgs.) Antropologia, impérios e estados nacionais. Rio de Janeiro: Relume-Dumará, 2002, p. 9. No que concerne à sociologia, ver, por exemplo: BERTHELOT, Jean-Michel. La construction de la sociologie. Paris: Presses Universitaires de France, 2006, p. 5.

42 Conforme ressalta Michel Alliot, "l'ethnologie juridique ne se définit plus par un domaine, mais par une méthode." apud NICOLAU, Gilda; PIGNARRE, Geneviève; LAFARGUE, Régis. Ethnologie juridique: 
a inversão radical da perspectiva de observação que o enfoque antropológico e o sociológico introduziram na análise do direito. ${ }^{43}$ De fato, se se considera o impacto que essas formas de "descrição externa" trouxeram para o conhecimento e compreensão do direito, ${ }^{44}$ fica evidente a importância do pensamento de Maine, uma vez que o mesmo, conforme será indicado a seguir, é considerado uma das bases de sustentação dessa nova compreensão do direito que se delineia a partir dos enfoques da antropologia e da sociologia, na segunda metade do século XIX.

\subsection{O impacto da tese de Maine na Antropologia Jurídica}

Vários autores consideram Maine um dos fundadores da antropologia jurídica. ${ }^{45}$ John Kelly, por exemplo, insere sua obra no âmbito do que denomina de "escola antropológica" que, segundo ele, seria um ramo da escola histórica da qual, entretanto, se distinguiria em razão de sua abordagem fortemente comparativa e pela ausência da convicção romântica no "espírito do povo" (Volksgeist).$^{46}$ Em sentido semelhante, Norbert

autour de trois exercices. Paris: Dalloz, 2007, p. 18. Em sentido semelhante, ver: COPANS, Jean. Da etnologia à antropologia. In: COPANS, Jean; TORNAY, Serge; GODELIER, Maurice; BACKÈSCLÉMENT, Catherine. Antropologia: ciência das sociedades primitivas? Tradução de J. Pinto de Andrade. Lisboa: Edições 70, 1988. p. 15. MOORE, Sally Falk. Certainties undone: fifty turbulent years of legal anthropology, 1949-1999. In: The Journal of the Royal Anthropological Institute. Vol. 7, n. 1, march 2001, p. 95. Esse artigo também integra o reader organizado pela autora com o título de Law and anthropology: a reader.

43 Cf. ASSIER-ANDRIEU, Louis. Diversité culturelle, diversité juridique: vues rétrospectives. In: CHAZEL, François; COMMAILLE, Jacques. (Dirs.) Normes juridiques et regulation sociale. Paris: L.G.D.J., 1991, p. 423.

44 André-Jean Arnaud e María José Fariñas Dulce explicitam muito bem essa especificidade ao ressaltarem que, a partir do século XIX, "il y a eu une sorte de différentiation entre ce qu'on appelait 'science juridique' ou 'science du droit' stricto sensu, qui traitait de l'étude du droit à partir d'un point de vue interne, et ce qu'on appelait 'sciences juridiques particulières' ou 'sciences sur le droit', qui abordaient l'étude du droit à partir d'une perspective externe, comme la sociologie du droit, la logique juridique, l'informatique juridique, l'histoire du droit, l'anthropologie juridique, l'ethnologie juridique, la biologie juridique, etc." ARNAUD, André-Jean; FARIÑAS DULCE, María José. Introduction à l'analyse sociologique des systèmes juridiques. Bruxelles: Bruylant, 1998, p. 4. A respeito, ver também: OST, François; KERCHOVE, Michel van de. De la scène au balcon. D'où vient la science du droit?. In: CHAZEL, François; COMMAILLE, Jacques. (Dirs.) Normes juridiques et régulation sociale. Paris: L.G.D.J., 1991, p. 72-77. Para uma análise dessa especificidade direcionada essencialmente à sociologia do direito, ver: LUHMANN, Niklas. Das Recht der Gesellschaft. Frankfurt am Main: Suhrkamp, 1993, p. 14. (trad. ingl., p. 57; trad. esp., p. 66);

Rechtssoziologie, p. 12.

45 Cumpre precisar que a antropologia jurídica não se confunde nem com a etnologia jurídica nem com a etnografia jurídica, uma vez que apresenta uma pretensão generalizadora que está ausente nas duas últimas perspectivas. Para uma definição da antropologia jurídica mediante um contraste com a etnologia jurídica e com a etnografia jurídica, ver: ROULAND, Norbert. Anthropologie jurídique, p. 122. Para uma definição genérica do campo da antropologia jurídica, ver: VANDERLINDEN, Jacques. Anthropologie juridique. Paris: Dalloz, 1996, p. 36. Para uma análise sintética da distinção entre antropologia, etnologia e etnografia, ver, por exemplo: DESCOLA, Philippe. Claude Lévi-Strauss, une présentation. In: La Lettre du Collège de France, hors de série n ${ }^{\circ}$ 2: Claude Lévi-Strauss, centième anniversaire. Paris: Collège de France, 2008, p. 5.

46 Cf. KELLY, John Maurice. Uma breve história da teoria do direito ocidental, p. 429. 
Rouland também enfatiza essa filiação da antropologia jurídica em relação à história do direito, indicando justamente o ano de 1861, em que ocorreram as publicações dos livros Das Mutterrecht de Johann Jakob Bachofen e Ancient Law de Henry James Sumner Maine, como o um marco no surgimento dessa disciplina. ${ }^{47}$

A obra de Maine se insere no âmbito da perspectiva evolucionista, que dominou a antropologia na segunda metade do século XIX. Dentre os antropólogos evolucionistas, encontram-se, por exemplo, Herbert Spencer (1820-1903), Lewis Morgan (1818-1881); James Frazer (1854-1941), Edward Burnett Tylor (1832-1917); John MacLennan (1827-1881); Johann Jakob Bachofen (1815-1887). Conforme será indicado a seguir, a perspectiva evolucionista, sobretudo em sua concepção unilinear, assume um viés etnocêntrico, uma vez que descreve o processo de evolução social em termos de transição do simples ao complexo, do rudimentar ao aperfeiçoado, ou do "primitivo" ao "civilizado". Nesse sentido, considera que as sociedades simples ou "primitivas" representariam um estágio de desenvolvimento original pelo qual a própria sociedade "civilizada" já teria passado. Conforme enfatiza Robert Deliège, os antropólogos evolucionistas estavam preocupados em procurar as origens das instituições modernas, por eles consideradas como o ponto final do desenvolvimento e do progresso humano de modo a propor, ao mesmo tempo, uma tipologia para a classificação das sociedades e das diversas culturas, mediante a definição das fases ou estágios de desenvolvimento pelos quais todos os grupos humanos passariam. ${ }^{48}$ Sublinhando justamente esse aspecto, Roberto Kant de Lima (2008, p. 5) ressalta que:

o início dos reflexos antropológicos sobre o Direito verificase nos quadros do evolucionismo social do século XIX (Maine, 1861; Bachofen, 1861; Maclennam [sic], 1865;

47 Conforme ressalta Norbert Rouland, "l'année 1861 est une date clef dans l'histoire de notre discipline. A Stuttgart et à Londres paraissent simultanément deux ouvrages capitaux: Das Mutterrecht, de J. J. Bachofen, inaugure l'ethnologie de la parenté [...]; mais c'est l'oeuvre de H. J. Sumner-Maine, Ancient Law (1861), suivie de Early History of Institutions (1875) et On Early Law and Custom (1883) qui a véritablement créé l'anthropologie juridique." ROULAND, Norbert. Anthropologie juridique, p. 49. Em sentido análogo, ver: EVANS-PRITCHARD, Edward Evan. Antropologia social. Tradução de Ana Maria Bessa. Lisboa: Edições 70, 1999, p. 34; SACCO, Rodolfo. Anthropologie juridique: apport à une macro-histoire du droit. Paris: Dalloz, 2008, p. 23. Por sua vez, Jean Copans - embora considere que a antropologia e a etnologia, enquanto disciplinas que teriam em comum o olhar sobre o outro, estejam inscritas no processo histórico que leva à emergência da modernidade ocidental, que se desenvolveria a partir do Renascimento - também enfatiza a importância do pensamento de Maine e Bachofen para o desenvolvimento da perspectiva evolucionista. Cf. COPANS, Jean. Introduction à l'ethnologie et à l'anthropologie, p. 37.

48 Cf. DELIÈGE, Robert. Anthropologie sociale et culturelle. 2e. édition. Bruxelles: De Boeck-Wesmael, 1995, p. 152; Une histoire de l'anthropologie. Écoles, auteurs, théories. Paris: Éditions du Seuil, 2006, p. 105. Acerca do etnocentrismo, ver, por exemplo: TODOROV, Tzvetan. Nous et les autres: la réflexion française sur la diversité humaine. Paris: Éditions du Seuil, 1989, p. 21-34; LÉVI-STRAUSS, Claude. Race et histoire. Paris: Denoël, 1987, p. 19-26. 
Durkheim, 1893). Tal perspectiva teórica, mais ou menos nítida de acordo com tendências intelectuais individuais, caracteriza-se por atribuir ao tempo a responsabilidade por transformações necessárias vistas como "estágios" de evolução social. Mais ou menos oculto nessa perspectiva, dependendo do autor, está o fato de que no topo da escala evolutiva situam-se sempre formas "superiores" e "complexas" de organização social encontradiças na sociedade do observador. ${ }^{49}$

Enfatizando esse caráter evolucionista que perpassa a obra de Maine, John M. Kelly sublinha a influência gerada por ela nos autores da antropologia jurídica, mesmo diante de seu progressivo desgaste. ${ }^{50}$ Em sentido análogo, Norbert Rouland ressalta que a teoria evolucionista de Maine teria sido objeto de amplo consenso na antropologia jurídica até meados do século XX. ${ }^{51}$ Para Rouland, o esquema evolucionista formulado por Maine teria sido inovador para época em que foi proposto, sobretudo se tomado como contraponto de teorias contratualistas. ${ }^{52}$ De fato, conforme já ressaltado, Maine critica intensamente essas teorias, rotulando-as de conjectural theories, justamente por discordar de seu caráter especulativo. Referindo-se expressamente a autores como Hobbes e Locke, considerados como exemplos de teorias fundadas em bases especulativas (speculative basis), Maine teria procurado enfatizar o quanto tais abordagens seriam insatisfatórias. ${ }^{53}$ Segundo ele,

49 KANT DE LIMA, Roberto. Ensaios de antropologia e de direito: acesso à justiça e processos institucionais de administração de conflitos e produção da verdade em uma perspectiva comparada. Rio de Janeiro: Lumen Juris, 2008, p. 5. Para uma problematização da caracterização de Durkheim como evolucionista, ver: BAECHLER, Jean. Un chef-d'œuvre d'Émile Durkheim: De la division du travail social. In: BOUDON, Raymond. Durkheim fut-il durkheimien? Actes du colloque organisé les 4 et 5 novembre 2008 par l'Académie des Sciences Morales et Politiques. Paris: Armand Colin, 2011, p. 15-18.

50 Cf. KELLY, John Maurice. Uma breve história da teoria do direito ocidental, p. 503 e ss. Para uma análise que sublinha essa influência no contexto francês, ver: ARNAUD, André-Jean. Critique de la raison juridique. 1. Où va la sociologie du droit? Paris: L.G.D.J., 1981, p. 84.

51 Veja-se, por exemplo: LEACH, Edmund R. The epistemological background to Malinowski empiricism. FIRTH, Raymond (ed.). Man and culture: an evaluation of the work of Bronislaw Malinowski. London: Routledge \& Kegan Paul, 1957, p. 137; GLUCKMAN, Max. Obrigação e dívida. In: DAVIS, Shelton H. Antropologia do direito: estudo comparativo de categorias de dívida e contrato. Tradução de Vera Maria Cândido Pereira. Rio de Janeiro: Zahar, 1973, p. 25- 56.

52 Cf. ROULAND, Norbert. Anthropologie juridique, p. 265.

53 Maine, embora não as deixe de criticar, exclui Montesquieu e Bentham dessas teorias que ele considera fundadas em bases especulativas. Segundo ele, "From the theories of jurisprudence which have the same speculative basis as the Roman doctrine two of much celebrity must be excepted. The first of them is that associated with the great name of Montesquieu. Though there are some ambiguous expressions in the early part of the Esprit des Lois, which seem to show its writer's unwillingness to break quite openly with the views hitherto popular the general drift of the book is certainly to indicate a very different conception of its subject from any which had been entertained before. [...] The other theory which has been adverted to is the historical theory of Bentham." MAINE, Henry James Sumner. Ancient Law, its Connection with the Early History of Society, and its Relation to Modern Ideas, p. 111-113. 
tais teorias cometeriam a impropriedade de não estarem fundadas em observações e sim em especulações acerca dos "estados arcaicos da sociedade" (archaic states of society). ${ }^{54}$

Conforme ressalta Edward E. Evans-Pritchard, em contraste com as perspectivas especulativas dos filósofos do século XVII e XVIII, o pensamento de Maine surge em meio a uma nova forma de análise das instituições sociais. Assim, de um lado, analisa a vertente francesa, destacando Montesquieu, D’Alembert, Condorcet, Turgot até Saint-Simon e, de outro, a inglesa, aludindo, sobretudo, a Hume e Smith para, em seguida, mostrar como delas surge, em meados do século XIX, a antropologia social. Referindo-se a essa distinção entre as perspectivas filosóficas dos séculos XVII e XVIII e a antropologia do século XIX, Evans-Pritchard enfatiza que as primeiras:

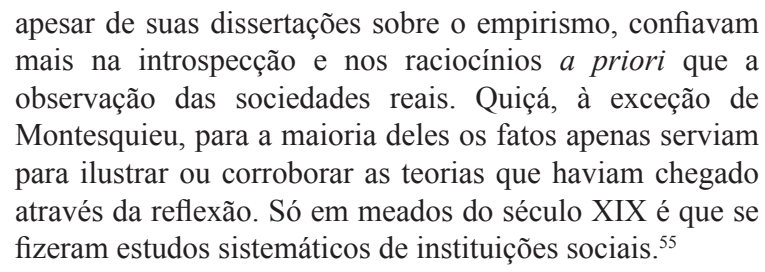

Evans-Pritchard enfatiza, ainda, que as pesquisas feitas pelos antropólogos do século XIX eram conduzidas a partir de uma postura muito mais crítica que a de seus predecessores. A esse respeito, observa que tais pesquisas não apenas estavam sustentadas por um conhecimento mais profundo que fundamentava suas generalizações como também o utilizavam de modo mais sistemático que os filósofos. Esse aspecto transparece claramente na obra de Maine. Com feito, é inquestionável o caráter sistemático das pesquisas empreendidas pelo autor escocês no que concerne às mudanças históricas sofridas pelo direito em meio às relações entre autoridade e sociedade. ${ }^{56}$ É justamente nesse contexto que Maine, criticando as teorias jusnaturalistas e contratualistas, ressalta, logo no início de Ancient Law, que as mesmas, apesar de gozarem de preferência em relação às pesquisas sérias acerca da "história primitiva" da sociedade e do direito, seriam carentes de verificação. Conforme Maine,

${ }_{54}$ Conforme enfatiza Maine, "there is such wide-spread dissatisfaction with existing theories of jurisprudence, and so general a conviction that they do not really solve the question they pretend to dispose of, as to justify the suspicion that some line of inquiry necessary to a perfect result has been incompletely followed or altogether omitted by their authors. And indeed there is one remarkable omission with which all these speculations are chargeable, except perhaps those of Montesquieu. [...] Their originators carefully observed the institutions of their own age and civilization, and those of other ages and civilizations with which they had some degree of intellectual sympathy, but, when they turned their attention to archaic states of society which exhibited much superficial difference from their own, they uniformly ceased to observe and began guessing." MAINE, Henry James Sumner. Ancient Law, its Connection with the Early History of Society, and its Relation to Modern Ideas, p. 114-115.

55 EVANS-PRITCHARD, Edward Evan. Antropologia social, p. 34.

56 Cf. PEÑA, Guillermo de la. Costumbre, ley y procesos judiciales en la antropología clásica: apuntes introductorios, p. 53. 
Theories, plausible and comprehensive, but absolutely unverified, such as the Law of Nature or the Social Compact, enjoy a universal preference over sober research into the primitive history of society and law; and they obscure the truth not only by diverting attention from the only quarter in which it can be found, but by that most real and most important influence which, when once entertained and believed in, they are enabled to exercise on the later stages of jurisprudence. ${ }^{57}$

Essa talvez seja a mais importante contribuição da obra de Maine para a antropologia jurídica. Mesmo que posteriormente suas generalizações tenham sido rejeitadas, atribuindo-se a elas o fato de estarem fundadas em dados insuficientes ou mal compreendidos, o fato é que Maine se esforçou por analisar a relação entre direito e sociedade a partir de uma perspectiva não especulativa, ainda que comprometida em seu alcance analítico em virtude de sua metodologia que, posteriormente, será taxada, não sem ironia, como expressão de uma perspectiva denominada de armchair anthropology. ${ }^{58}$ Aliás, conforme enfatiza Dan Sperber, é justamente esse esforço de superação de uma abordagem especulativa que marca, em meados do século XIX, o surgimento da antropologia em sentido estrito. ${ }^{59}$ A respeito, Evans-Pritchard, enfatiza que “a 'investigação séria' de Maine e seus contemporâneos abriu o caminho para a compreensão das instituições sociais. Ao selecionar e classificar o material recolhido, eles constituíram um corpo fundamental de dados etnográficos, que até aí não existia, donde se podia extrair significativas conclusões teóricas e provar a sua validade. ${ }^{90}$

57 MAINE, Henry James Sumner. Ancient Law, its Connection with the Early History of Society, and its Relation to Modern Ideas, p. 3.

58 Conforme ressalta Alfred Reginald Radcliffe-Brown, os "antropólogos de gabinete" (armchair anthropologists), tais como James Frazer, autor do célebre Golden Bough, caracterizar-se-iam pelo fato de trabalharem em bibliotecas (they work in libraries). Cf. RADCLIFFE-BROWN, Alfred Reginald. The comparative method in social anthropology. In: KUPER, Adam (Ed.). The social anthropology of RadcliffeBrown. London: Routledge \& Kegan Paul Ltd., 1977, p. 54. Referindo-se aos antropólogos evolucionistas, dentre os quais Maine, Norbert Rouland ressalta que "ils font de l'anthropologie comme s'il étaient des historiens, en travaillant en cabinet sur des documents de nature diverse, ce qui accentuera leur propension aux généralisations hâtives, que démentira par la suite l'observation ethnographique." ROULAND, Norbert. Anthropologie juridique, p. 59. No mesmo sentido, Robert Deliège ressalta que "les premiers anthropologues vont fonder leurs théories sur des matériaux de seconde main, principalement des récits de voyageurs, des écrits de missionnaires, des rapports officiels, ou diverses sources historiques et archéologiques.” DELIĖGE, Robert. Anthropologie sociale et culturelle, p. 151. Cabe aqui mencionar a clássica crítica que Bronislaw Malinowski endereçou a certos pressupostos da teoria de Maine acerca do direito que foram desmentidos por sua pesquisa de campo nas ilhas Trobriand. A respeito, ver: MALINOWSKI, Bronislaw. Crime and Custom in Savage Society, p. 55-59.

59 Cf. SPERBER, Dan. O saber dos antropólogos. Tradução de José Martha Aragão. Lisboa: Edições 70, 1992, p. 11-12.

60 EVANS-PRITCHARD, Edward Evan. Antropologia social, p. 40. 


\subsection{O impacto da tese de Maine na Sociologia do Direito}

Niklas Luhmann enfatiza o caráter inovador assumido pela abordagem sociológica em relação à tradição doutrinária (Lehrtradition), desenvolvida na Europa, no que concerne à análise da relação entre direito e sociedade. Segundo Luhmann, nessa tradição o direito seria encarado como um dado essencial e inerente às associações humanas, de modo a ser concebido como imanente à natureza e enredado indissoluvelmente a outros traços característicos da sociedade, tais como as relações de amizade e as relações de hierarquia e de dominação. ${ }^{61}$

Assim, para o pensamento jusnaturalista, o convívio na sociedade humana não delinearia apenas uma normatividade abstrata, uma vez que engendraria, além disso, normas determináveis em sua substância e capazes de reivindicar para si um surgimento e uma verdade naturais. Nesse sentido, além de sustentar a ligação indissolúvel entre direito e sociedade, essa tradição também postularia uma segunda tese consistente na existência de certas normas que seriam igualmente válidas a todas as sociedades. Entretanto, segundo Luhmann, as próprias comparações históricas e etnográficas realizadas a partir do século XIX teriam solapado essa pretensão de postular invariâncias normativas de modo a indicar o caráter contingente na formação do direito. ${ }^{62}$

É nesse ponto que, segundo ele, a sociologia do direito, que surge na segunda metade do século XIX, se afastaria dessa tradição de análise da relação entre direito e sociedade. Para Luhmann, também a sociologia poderia aceitar a tese do liame indissolúvel entre direito e sociedade, porém não a postulação que dela se segue de que, em virtude desse liame, haveria certas normas jurídicas igualmente válidas para todas as sociedades. Nesse sentido, a Sociologia do Direito enfocaria o direito como um construto em princípio indispensável, porém formado a partir da contingência das relações humanas sendo, portanto, também ele contingente e desprovido de normas com pretensão de validade genérica. ${ }^{63}$

Segundo Luhmann, o distanciamento em relação à "visão interna" do direito e sua fundamentação moral caracterizaria os esforços do que ele denomina de "abordagens clássicas da sociologia do direito". ${ }^{64}$ Para Luhmann, essas abordagens seriam compreendidas como sociológicas justamente em virtude desse distanciamento ${ }^{65}$ e à

\footnotetext{
${ }_{61}$ Cf. LUHMANN, Niklas. Rechtssoziologie, p. 10.

62 Cf. LUHMANN, Niklas. Rechtssoziologie, p. 11.

63 Cf. LUHMANN, Niklas. Rechtssoziologie, p. 11.

64 Cf. LUHMANN, Niklas. Rechtssoziologie, p. 12.

65 Em obras posteriores, sobretudo no livro intitulado Das Recht der Gesellschaft, Luhmann se referirá à especificidade da abordagem sociológica acerca do direito em termos de "descrição externa" (Fremdbeschreibung). Cf. LUHMANN, Niklas. Das Recht der Gesellschaft. Frankfurt am Main: Suhrkamp, 1993, 15-17 (trad. ingl., p. 58-60; trad. esp., p. 68-70).
} 
avaliação da moral a partir de perspectivas incongruentes. Nesse contexto, apesar das diferenças entre as diversas versões dessas "abordagens clássicas da sociologia do direito", seria possível reconhecer algumas premissas que lhes seriam comuns, quais sejam: a) o direito, como estrutura normativa, é diferenciado da sociedade, como um conjunto fático de vida e de ação (Das Recht ist nicht mehr die Gesellschaft); b) direito e sociedade passam a ser definidos como duas variáveis dependentes entre si cuja correlação, no século XIX, é concebida, em sua variação, em termos evolucionistas, como expressão de um progresso regular da civilização; c) em tais condições são estabelecidas hipóteses empiricamente controláveis e verificáveis sobre a relação entre direito e sociedade a partir de observações da correlação em suas variações. ${ }^{66}$

Após identificar essas premissas comuns, Luhmann realiza uma compilação comparativa de algumas das mais expressivas variações das "abordagens clássicas da sociologia do direito" que encontrariam expressão típica nas obras de Henry J. Sumner Maine, Karl Marx, Émile Durkheim e Max Weber, na qualidade de autores típicos, e nas de Eugen Ehrlich e de Talcott Parsons como "autores atípicos". ${ }^{67}$ Nesse contexto, Henry J. Sumner Maine é alçado por Luhmann à posição de um dos formadores da sociologia do direito. É certo que sua teoria se mostrará datada e será objeto de intensa crítica. ${ }^{68}$ Entretanto, ela apresenta inquestionavelmente uma contribuição à formação da sociologia. Segundo Luhmann, sua descrição da evolução do direito em termos de passagem do status ao contrato teria enunciado, em linhas gerais, ainda que de forma insuficientemente, o modo pelo qual se procurará descrever a relação entre a configuração concreta assumida pelo direito e as estruturas sociais que se tornam progressivamente mais complexas. ${ }^{69}$ Conforme enfatiza Luhmann, essa temática forneceria, uma geração mais tarde, com a obra de Émile Durkheim, um novo impulso, desta vez propriamente sociológico, à sociologia do direito. ${ }^{70}$ Por outro lado, ainda no que concerne ao domínio da abordagem sociológica, cabe mencionar que, segundo Talcott Parsons, a obra de Maine

${ }_{66}$ Cf. LUHMANN, Niklas. Rechtssoziologie, p. 12.

67 Cf. LUHMANN, Niklas. Rechtssoziologie, p. 12 e ss. Para uma análise que contrasta o pensamento de Durkheim com o de Luhmann, ver: VILLAS BÔAS FILHO, Orlando. A sociologia do direito: o contraste entre a obra de Émile Durkheim e a de Niklas Luhmann. In: Revista da Faculdade de Direito da USP, vol. 105, p. 561-593, jan./dez. 2010.

68 Conforme ressalta Renato Treves, as teses de Maine também serão objeto de crítica no âmbito da sociologia do direito. Segundo ele, Lawrence M. Friedman, por exemplo, enfatizará nela a presença de referências ideológicas e a dificuldade de aplicação de uma concepção evolutiva ao direito. Cf. TREVES, Renato. Sociologia do direito: origens, pesquisas e problemas, p. 328

69 Cf. LUHMANN, Niklas. Rechtssoziologie, p. 15.

70 Cf. LUHMANN, Niklas. Rechtssoziologie, p. 15. Nesse particular, vale reiterar, seguindo Camille Tarot, que Durkheim assumiu uma posição crítica em relação ao evolucionismo inglês. Cf. TAROT, Camille. Sociologie et anthropologie de Marcel Mauss, p. 30-33. 
teria influenciado a elaboração da clássica distinção proposta por Ferdinand Tönnies entre comunidade (Gemeinschaft) e sociedade (Gesellschaft). ${ }^{71}$

$\mathrm{O}$ enquadramento da obra de Maine no âmbito da sociologia do direito se aclara à luz da classificação apresentada por Renato Treves em sua obra Sociologia del diritto. Treves aponta três concepções diferentes da sociologia do direito: a) a concepção que a liga à sociologia geral; b) a concepção que a liga à teoria geral do direito; c) a concepção que a liga às sociologias particulares que se ocupam essencialmente de pesquisas empíricas. Tomada essa classificação, obras clássicas como a Maine e a de Durkheim seriam expressão da primeira concepção da sociologia do direito, ou seja, aquela que mantém um liame com sociologia geral. Aliás, para ilustrar essa concepção de sociologia do direito, Treves alude justamente à tese da passagem do status ao contrato e à da passagem da solidariedade mecânica à solidariedade orgânica. ${ }^{72}$

\section{Henry James Sumner Maine e o Evolucionismo}

Referindo-se à especificidade da ambiência intelectual do século XIX, Robert Deliège ressalta a preocupação que atravessou esse período relativamente à classificação dos povos e das instituições sociais a partir de sequências evolutivas. ${ }^{73}$ Em meio a essa preocupação encontrava-se, ainda, a tentativa de especificar as origens de tais instituições.

71 Cf. PARSONS, Talcott. The structure of social action. A study in social theory with special reference to a group of recent european writers. New York: The Free Press, 1968, p. 687. Em sentido análogo, ver: LUHMANN, Niklas. Rechtssoziologie, p. 309, nota 32; ARNAUD, André-Jean. Critique de la raison juridique. 1. Où va la sociologie du droit?, p. 105. Sobre a distinção entre Gemeinschaft e Gesellschaft, ver: TÖNNIES, Ferdinand. Communauté et société. In: DANIEL, Jean (Dir.) La société: les plus grands texts d'Auguste Comte et Émile Durkheim à Claude Lévi-Strauss. Paris: Le Nouvel Observateur/CNRS Éditions, 2011, p. 131-219. A respeito, ver também: KROTZ, Esteban. Sociedades, conflictos, cultura y derecho desde una perspectiva antropológica, p. 13. Para uma análise da relação entre Tönnies e Durkheim, ver também: ALDOUS, Joan; DURKHEIM, Émile; TÖNNIES, Ferdinand. An Exchange between Durkheim and Tönnies on the nature of social relations, with an introduction by Joan Aldous. In: American journal of sociology. Vol. 77, Issue 6 (may, 1972), p. 1191-1200. Para uma análise da influência alemã na sociologia francesa do final do século XIX e início do XX, ver: PAPILLOUD, Christian. Simmel, Durkheim et Mauss. Naissance ratée de la sociologie européenne. In: Revue du MAUSS, 2000/2 (n. $\left.{ }^{\circ} 20\right)$, p. 312-313.

72 Cf. TREVES, Renato. Sociologia del diritto, p. 1-8 apud ANDRINI, Simona; ARNAUD, André-Jean. Jean Carbonnier, Renato Treves et la sociologie du droit: archéologie d'une discipline (entretiens et pièces). Paris: L.G.D.J., 1995, p. 165-173. Para uma análise introdutória acerca da especificidade das abordagens dos juristas e dos sociólogos do direito, ver: SERVERIN, Évelyne. Sociologie du droit. Paris: La Découverte, 2000, p. 4-8.

73 Conforme enfatiza Deliège "au cours du XIXe siècle, la théorie de l'évolution des espèces allait prendre une telle ampleur qu'elle devint quasiment une sorte d'idéologie nationale et la plupart des hommes de science tâchèrent de montrer que les faits observes ou rapportés s'intègrent dans les grandes séquences d'évolution qu'ils avaient préalablement construites. En ce sens, on peut dire que la démarche des évolutionnistes n'est pas inductive, mais elle est plutôt 'hypothético-déductive' et l'on peut parler d'une véritable théorie évolutionniste qui vise à rendre compte de l'histoire de l'humanité, de la place des différentes institutions de l'homme au sein de cette histoire et des différences qui séparent les sociétés de la planète." DELIÈGE, Robert. Anthropologie sociale et culturelle, p. 143. 
Nesse contexto, a evolução aparecia em termos de um desenvolvimento progressivo em meio ao qual as formas mais "avançadas" de uma instituição eram consideradas superiores às formas "primitivas". ${ }^{74}$ A respeito, Deliège propõe o seguinte quadro que resumiria as classificações de então acerca da diferença entre "povos superiores" e "povos inferiores".

\section{Quadro comparativo proposto por robert deliège relativamente às classificações dos povos segundo o modelo evolucionista ${ }^{75}$ :}

\begin{tabular}{|c|c|}
\hline Peuples inférieurs & Peuples supérieurs \\
\hline Raisonnement enfantin & Raisonnement scientifique \\
Absence d'invention & Capacité technologique \\
Anarchie ou tyrannie & Démocratie parlamentaire \\
Communisme primitif & Propriété privée \\
Communisme sexuel, promiscuité & Monogamie \\
Ignorance religieuse, amoralité & Monothéisme, moralité \\
\hline
\end{tabular}

Guillermo de la Peña ressalta que o século XIX poderia ser denominado "século do evolucionismo" não apenas porque nele as teorias biológicas de Jean-Baptiste Lamarck e Charles Darwin ocuparam o centro do debate intelectual durante várias décadas, mas porque os estudiosos da sociedade também teriam adotado um enfoque análogo em suas pesquisas. ${ }^{76}$ É nesse contexto que se situa a obra de Maine e de outros célebres autores evolucionistas, tais como Morgan, Bachofen e Tylor. ${ }^{77}$

Ao analisar as ideias fundamentais de algumas das posições clássicas da antropologia jurídica entre o século XIX e meados do século XX, Esteban Krotz, referindose à perspectiva evolucionista, ressalta que a mesma seria caracterizada por dois aspectos fundamentais: a) a ideia de que todos os povos, mesmo os considerados "primitivos" ou "selvagens", seriam portadores de cultura e de potencial de desenvolvimento, o que permitia inferir que estariam subsumidos a algum tipo de ordem; b) a ideia de que toda ordem estaria submetida a um processo de desenvolvimento permanente que, ademais, se

74 Cf. DELIÈGE, Robert. Anthropologie sociale et culturelle, p. 149-150; Une histoire de l'anthropologie. Écoles, auteurs, théories, p. 18.

75 Cf. DELIÈGE, Robert. Anthropologie sociale et culturelle, p. 151; l'anthropologie. Écoles, auteurs, théories, p. 20.

76 PEÑA, Guillermo de la. Costumbre, ley y procesos judiciales en la antropología clásica: apuntes introductorios, p. 52. A respeito, Norbert Rouland considera Maine um "evolucionista darwiniano". Cf. ROULAND, Norbert. Anthropologie Juridique, p. 50.

77 A esse respeito, Jean Copans ressalta que "une conception linéaire de l'évolution, na notion de progrès, l'existence d'étapes dans son développement, une conception plutôt internaliste des causes du changement constituent l'essentiel des idées de ce courant théorique et philosophique. Au début, ces préoccupations relevaient principalement des études juridiques, dans la mesure où elles portaient sur le mariage, la famille, la propriété privée, l'État. C'est d'ailleurs l'ouvrage du Britannique Henry Maine, Ancient Law (1861), qui sert de point de depart à ces réflexions." COPANS, Jean. Introduction à l'ethnologie et à l'anthropologie. 3e Édition. Paris: Armand Colin, 2010, p. 36. 
aplicaria também às ordens normativas, como o direito, por exemplo. ${ }^{78}$ Fica evidente, portanto, que o evolucionismo é marcado por um enfoque essencialmente diacrônico, uma vez que procura captar a mudança social no bojo da temporalidade histórica, descrevendo-a, ademais, a partir da enunciação de supostas leis gerais que regeriam o processo evolutivo. ${ }^{79}$

Diante disso, verifica-se que o evolucionismo do século XIX apresenta, como bem o nota Norbert Rouland, outras características importantes, tais como: a) a ideia de que as sociedades humanas formariam um conjunto coerente e unitário, subsumido a leis de transformação globais e gerais $;^{80} \mathrm{~b}$ ) a suposição de que todos os grupos humanos passariam por estágios idênticos e sucessivos no desenvolvimento de suas organizações econômicas, sociais e jurídicas, ${ }^{81}$ c) uma concepção linear do tempo, decorrente da pressuposição de que o movimento evolutivo seria progressivo e submetido a fases idênticas e sucessivas, ${ }^{82}$ d) a ausência de pesquisa de campo. ${ }^{83}$

Conforme ressalta Norbert Rouland, esse esquema corresponde à apresentação clássica da distinção entre sociedades tradicionais e modernas. Baseando-se essencialmente no pensamento de Durkheim, Rouland ressalta que, para as perspectivas evolucionistas, as sociedades tradicionais seriam caracterizadas por uma forte integração do indivíduo a grupos e dos grupos entre si, mediante um amalgama entre as dimensões política, religiosa e jurídica, fundado numa solidariedade de tipo mecânico, enquanto que as sociedades modernas caracterizar-se-iam por uma diferenciação social acentuada e por uma solidariedade de tipo orgânico. ${ }^{84} \mathrm{O}$ Estado seria, nesse sentido, uma das expressões institucionais desta diferenciação, e o direito, conquistando sua autonomia em relação a

78 Cf. KROTZ, Esteban. Sociedades, conflictos, cultura y derecho desde uma perspectiva antropológica. In: _ (Ed.) Antropología jurídica: perspectivas socioculturales en el estudio del derecho. Rubí (Barcelona): Anthropos Editorial; México: Universidad Autónoma Metropolitana - Iztapalapa, 2002, p. 1819.

79 Cf. ROULAND, Norbert. Anthropologie juridique, p. 59.

$80 \quad$ Cf. ROULAND, Norbert. Anthropologie juridique, p. 57.

81 Cf. ROULAND, Norbert. Anthropologie juridique, p. 55. Em sentido análogo, ver: DELIÈGE, Robert. Anthropologie sociale et culturelle, p. 152.

82 Cf. ROULAND, Norbert. Anthropologie juridique, p. 58; L'Anthropologie juridique, p. 33. Em sentido análogo, ver: DELIÈGE, Robert. Anthropologie sociale et culturelle, p. 152.

83 Nesse particular, referindo-se aos evolucionistas, Rouland ressalta que "ils font de l'anthropologie comme s'il étaient des historiens, en travaillant en cabinet sur des documents de nature diverse, ce qui accentuera leur propension aux généralisations hâtives, que démentira par la suíte l'observation ethnographique." ROULAND, Norbert. Anthropologie juridique, p. 59. Em sentido análogo, ver: DELIÈGE, Robert. Anthropologie sociale et culturelle, p. 151.

84 Cf. ROULAND, Norbert. Anthropologie juridique, p. 56; DURKHEIM, Émile. De la division du travail social. 7e édition. Paris: Presses Universitaires de France, 2007, p. 99-102. Para um comentário do pensamento sociológico de Durkheim acerca das formas de solidariedade, ver: VILLAS BÔAS FILHO, Orlando. A sociologia do direito: o contraste entre a obra de Émile Durkheim e a de Niklas Luhmann, p. $570-571$. 
outras formas de regulação social, encontraria a condição fundamental de sua expansão. ${ }^{85}$ Rouland ressalta que, nessa perspectiva, todo o progresso evolutivo deve ser traduzido por um implemento de complexidade. ${ }^{86}$

Segundo Rouland, essa insistência do evolucionismo na descrição da evolução em termos de aumento de complexificação pode conduzir ao etnocentrismo, na medida em que ela torna fácil a assimilação da transição do simples ao complexo, do rudimentar ao aperfeiçoado, e do primitivo ao civilizado. ${ }^{87}$ Deste modo, concebe-se as sociedades simples ou "primitivas" como representantes de um estágio de desenvolvimento original pelo qual nossa própria sociedade já teria passado. Assim, postula-se que, no plano político, a evolução conduziria as formas dispersas de dominação às formas centralizadas e estatais enquanto que, analogamente, no plano jurídico, a evolução do direito se processaria em termos de uma progressiva separação em relação à moral e à religião. Nessa perspectiva, o direito transferiria sua gênese do costume do grupo social para a lei posta pelo Estado. Ocorreria, assim, a emergência do aparelho estatal organizado e dos aparelhos especializados de sanção (tribunais/juízes/árbitros) que, por esse motivo, deixaria de ser aplicada de forma difusa. ${ }^{88}$

É possível, ainda, indicar mais uma importante característica que atravessa as teorias evolucionistas do século XIX. Trata-se da associação entre evolução social e progresso tecnológico. ${ }^{89}$ Célebres autores evolucionistas insistirão bastante nesse aspecto. Lewis H. Morgan, por exemplo, numa das obras mais influentes da perspectiva evolucionista do século XIX, Ancient Society, atrelava estreitamente a evolução social a etapas de progresso tecnológico. Assim, para ele, a passagem da selvageria à barbárie e desta à civilização decorreria, essencialmente, do desenvolvimento da técnica. ${ }^{90}$ Argumento de feição semelhante também se encontra expresso na obra de Marx e Engels e, no século XX, nos clássicos trabalhos de Gordon Childe e Leslie White. ${ }^{91}$ Não cabe, recuperar aqui

\footnotetext{
85 Cf. ROULAND, Norbert. Anthropologie juridique, p. 56.

86 Cf. ROULAND, Norbert. Anthropologie juridique, p. 56.

87 Cf. ROULAND, Norbert. Anthropologie juridique, p. 57.

88 Cf. ROULAND, Norbert. Anthropologie juridique, p. 58.

89 Referindo-se ao evolucionismo, Robert Deliège ressalta que, para ele, "la société victorienne est la plus avancée de toutes; si les hommes primitifs étaient plus intelligents, dit Lyall, nous aurions trouvé des vestiges de lignes de chemin de fer, des microscopes et peut-être même des machines pour naviguer das les airs ou explorer les océans.” DELIÈGE, Robert. Anthropologie sociale et culturelle, p. 150.

90 Cf. MORGAN, Lewis Henry. Ancient society, or researches in the lines of human progress form savagery throught barbarism to civilization. New Brunswick, New Jersey: Transaction Publishers, 2000, especialmente, caps. I e III. Para uma análise sintética do pensamento de Morgan, com ênfase em seus contornos jurídicos, ver: ROULAND, Norbert. Anthropologie juridique, p. 51-52.

91 Para uma abordagem sintética dessas teorias clássicas do evolucionismo, ver: RIBEIRO, Darcy. O processo civilizatório: etapas da evolução sociocultural. São Paulo: Companhia das Letras; Publifolha, 2000, p. 2-6. A respeito, para uma análise que contrasta a perspectiva de Morgan com a de Marx e Engels, ver: ROULAND, Norbert. Anthropologie juridique, p. 51-54. A respeito, ver também: FALK MOORE, Sally. Law and Anthropology: a reader. Malden/USA: Blackwell, 2005, p. 20-31; 108.
} 
esse aspecto em maior detalhe. Em todo caso, cumpre notar, seguindo a análise de Norbert Rouland, que, no século XIX, a noção de desenvolvimento será paulatinamente associada à de progresso e o evolucionismo jogará um papel importante para tanto. ${ }^{92}$

De um modo geral, os conceitos desenvolvidos no âmbito das teorias evolucionistas, sobretudo em razão de sua forte carga etnocêntrica, poderiam ser caracterizados como "conceitos antitéticos assimétricos", no sentido dado por Reinhart Koselleck. ${ }^{93}$ Tais conceitos, caracterizar-se-iam por imprimir um significado depreciativo a um indivíduo ou grupo em comparação com outro indivíduo ou grupo, de modo que os primeiros poderiam se considerar designados, porém não reconhecidos. ${ }^{94}$ Tais designações opostas serviriam para estabelecer inclusões e exclusões, ${ }^{95}$ uma vez que do conceito utilizado para designar a si próprio decorreria a denominação usada para designar o outro, para o qual, entretanto, a designação equivaleria, linguisticamente, a uma privação. Ou seja, dados dois conceitos reciprocamente relacionados de forma antitética, verificar-se-ia que estes seriam também assimétricos quando marcados por uma desigualdade constitutiva que tolhe de um dos conceitos a capacidade de reconhecimento em relação ao individuo ou ao grupo que por ele são designados. ${ }^{96}$ Ora, falar em "civilizado" em oposição a "selvagem" ou "bárbaro", de "moderno" em oposição a "primitivo" ou de "povo superior" em oposição a "povo inferior" é justamente desqualificar um grupo em oposição a outro que, por essa razão, passa a ser qualificado positivamente. $\mathrm{O}$ evolucionismo, em meio ao qual se situa a obra de Maine, a partir de uma perspectiva etnocêntrica, fez uso de designações conceituais desse tipo de forma recorrente. ${ }^{97}$

\section{As "afinidades eletivas" entre evolucionismo e imperialismo}

Baseando-se na noção de "afinidade eletiva" utilizada por Max Weber para descrever a relação entre a "ética protestante" e o "espírito do capitalismo", os antropólogos Benoît de L'Estoile, Federico Neiburg e Lygia Sigaud procuram sublinhar

92 Cf. ROULAND, Norbert. L'anthropologie juridique, p. 33.

93 Cf. KOSELLECK, Reinhart. Vergangene Zukunft. Zur Semantik geschichtlicher Zeiten. Frankfurt am Main: Suhrkamp, 1989, p. 211 e ss. (trad. bras., p. 191 e ss).

94 Tais atributos que só podem ser usados em uma direção e que na direção contrária seriam diferentes, são denominados por Koselleck de "assimétricos". Cf. KOSELLECK, Reinhart. Vergangene Zukunft. Zur Semantik geschichtlicher Zeiten, p. 211 (trad. bras., p. 191).

95 Koselleck ressalta que uma unidade de ação política só se constitui por meio de conceitos pelos quais ela se delimita, excluindo outras, de modo a determinar a si mesma. Cf. KOSELLECK, Reinhart. Vergangene Zukunft. Zur Semantik geschichtlicher Zeiten, p. 212 (trad. bras., p. 192).

96 Cf. Id. Ibid., p. 213 (trad. bras., p. 193).

97 Cf. DA MATTA, Roberto. Repensando E. R. Leach. In: DA MATTA, Roberto (Org.). Edmund Ronald Leach: antropologia. Tradução de Alba Zaluar Guimarães. São Paulo: Ática, 1983, p. 9-10. (Col. Grandes Cientistas Sociais) 
as "afinidades eletivas"98 existentes entre a antropologia do século XIX, fortemente influenciada pelo evolucionismo, e a expansão imperialista. Anoção de "afinidade eletiva", tal como utilizada por esses autores, expressaria justamente a imbricação recíproca entre o saber dos antropólogos e a dominação colonial. Ou seja, a administração colonial apoiaria o desenvolvimento de instituições acadêmicas especializadas na produção de saber sobre as populações nativas - tais como museus, expedições etnográficas, departamentos universitários, institutos de pesquisa etc. - e os antropólogos, apesar de muitas vezes manterem posturas críticas em relação às atividades de seus Estados de origem, forneceriam conhecimentos que, em última instância, se prestariam à validação das políticas coloniais. Tratar-se-ia, entretanto, de uma relação entre a produção do conhecimento antropológico e a administração colonial que não se processa de forma mecânica ou de causa e efeito. ${ }^{99}$

98 Como se sabe, Weber, em seu célebre livro intitulado A ética protestante e o espírito do capitalismo, ressalta justamente a relação não causal, mas de afinidade entre o ascetismo intramundano do protestantismo e o "espírito do capitalismo". Nesse particular, Jean-Jacques Guinchard sublinha que "“Affinités électives' (Wahlverwandschaften) signifie littéralement des parentés de choix, par opposition à la parenté de fait, non choisie. Goethe en a fait le titre d'un roman centré sur les difficultés de l'affectivité moderne (1809), reprenant une formule-clef de l'alchimie traditionnelle; donc Weber fait ici allusion à une attraction et à une rencontre mystérieuses, et pourtant nécessaires." GUINCHARD, Jean-Jacques. Max Weber: vie, oeuvres, concepts. Paris: Éditions Ellipses, 2006, p. 40. Para uma utilização da noção de "afinidade eletiva" no tratamento da relação entre a produção do conhecimento (no caso a antropologia de orientação evolucionista) e a administração (no caso o colonialismo), ver: L'ESTOILE, Benoît de; NEIBURG, Federico; SIGAUD, Lygia. Antropologia, impérios e estados nacionais: uma abordagem comparativa. In: L'ESTOILE, Benoît de; NEIBURG, Federico; SIGAUD, Lygia (Orgs.). Antropologia, impérios e estados nacionais. Rio de Janeiro: Relume Dumará, 2000, p. 21; L'ESTOILE, Benoît de. Ciência do homem e "dominação racional": saber etnológico e política indígena na África colonial francesa. In: L'ESTOILE, Benoît de; NEIBURG, Federico; SIGAUD, Lygia (Orgs.). Antropologia, impérios e estados nacionais, p. 61 e ss. Para uma análise do termo em Weber, ver: SWEDBERG, Richard. The Max Weber dictionary: key words and central concepts. Stanford: Stanford University Press, 2005, p. 83-84.

99 É justamente por isso que a antropologia do século XIX poderia ser descrita, em linhas gerais, como uma espécie de saber que mantém "afinidades" com a "gestão de populações" uma vez que teria se prestado à fundamentação do governo, à administração e ao controle dos povos colonizados. Cf. L’ESTOILE, Benoît de. Ciência do homem e "dominação racional": saber etnológico e política indígena na África colonial francesa. In: L’ESTOILE, Benoît de; NEIBURG, Federico; SIGAUD, Lygia. (Orgs.) Antropologia, impérios e estados nacionais, p. 61 e ss. Contudo, conforme enfatiza Talal Asad, apesar de manter ligações irrefutáveis com o colonialismo, não é correto considerar a antropologia apenas uma ferramenta da dominação colonial ou um simples reflexo da ideologia que dava esteio a essa dominação. A antropologia moderna, enraizada que está na consciência burguesa, apresentou ao longo de seu desenvolvimento contradições ambivalências que lhe permitiram transcender suas determinações de origem. É inegável que o saber antropológico serviu à dominação, sobretudo durante o século XIX, porém, não se limitou apenas a essa dimensão, pois a relação entre antropologia e dominação colonial é complexa e ambígua e, por isso, não se reduz apenas à simples instrumentalização da primeira pela segunda. Malgrado essa relação esteja enraizada na assimetria inerente à relação entre dominadores e dominados e na tendência de se imprimir a visão e a racionalidade ocidentais às demais sociedades, é preciso considerar que nem por isso a antropologia foi um simples reflexo de uma situação de fato, caracterizada por violência e espoliação. Ainda que tenha contribuído indiretamente para a dominação colonial, a antropologia, mesmo nesse período, também se caracterizou por posturas críticas. Cf. ASAD, Talal. Two European images of nonEuropean rule. In: ASAD, T. (Ed.) Anthropology \& the colonial encounter. $7^{\mathrm{a}}$ Ed. New Jersey: Humanities 
O desenvolvimento da antropologia dependeu, em certa medida, da existência da dominação colonial, uma vez que esta garantia aos pesquisadores seu campo de observação e análise. Entretanto, a relação entre esses dois âmbitos (saber antropológico e dominação colonial) é complexa. ${ }^{100}$ De qualquer modo, conforme ressalta Jean Copans, teria havido uma afinidade bastante clara entre a relação de subjugação dos povos "não-europeus" pelo "messianismo ocidental", típico do fim do século XIX, e as teorias evolucionistas que, fundadas em concepções etnocêntricas, forneceram a base ideológica para legitimar essa dominação. ${ }^{101}$ Seria possível, portanto, enxergar nas perspectivas evolucionistas a expressão de uma postura etnocêntrica que perpassa a relação do colonizador europeu com os povos colonizados, fundamentando discursivamente a sua assimetria. ${ }^{102}$ A obra de Maine se insere no bojo desse processo de modo a ser considerada, inclusive, um dos pilares da antropologia evolucionista que - direcionada ao estudo dos "povos primitivos" e baseada no pressuposto etnocêntrico de que as sociedades ocidentais seriam superiores às demais, pois constituiriam o desfecho de um processo evolutivo unilinear e pautado por etapas sucessivas de desenvolvimento - forneceu uma justificação teórica para o exercício da dominação colonial. ${ }^{103}$

Press: Atlantic Highlands, 1995, p. 103-118. ROULAND, Norbert. L'anthropologie juridique, p. 17-18. A respeito, ver também: VILLAS BÔAS FILHO, Orlando. A constituição do campo de análise e de pesquisa da antropologia jurídica. In: Prisma Jurídico. São Paulo, v. 6, p. 333-349, 2007.

100 Wendy James, por exemplo, enfatiza a relação de dependência dos antropólogos com os agentes coloniais, o que, segundo ele, teria acarretado uma situação duplamente ambivalente para a antropologia, no contexto da dominação colonial. De um lado, teria havido ambivalência na relação entre a atuação dos antropólogos, no que concerne à fundamentação de uma dominação, para a qual eram instados a colaborar, mesmo discordando e, de outro, diante dos movimentos nacionalistas e revolucionários, a antropologia, inicialmente vista de modo positivo, paulatinamente passava a ser considerada conservadora. Em razão dessa dupla ambivalência, explicar-se-iam as acusações e suspeitas que recaíram sobre a antropologia, durante o período colonial, a partir das mais variadas instâncias. Cf. JAMES, Wendy. The anthropologist as reluctant imperialist. In: ASAD, Talal. (Ed.) Anthropology \& the colonial encounter. 7. ed. New Jersey: Humanities Press: Atlantic Highlands, 1995, p. 42-43.

101 Cf. COPANS, Jean. Da etnologia à antropologia. In: COPANS, Jean; TORNAY, Serge; GODELIER, Maurice; BACKÈS-CLÉMENT, Catherine. Antropologia: ciência das sociedades primitivas?, p. 14.

102 A respeito, Claude Lévi-Strauss ressalta que "l'anthropologie est fille d'une ère de violence; et si elle s'est rendue capable de prendre des phénomènes humains une vue plus objective qu'on ne le fasait auparavant, elle doit cet avantage épistémologique à un état de fait dans lequel une partie de l'humanité s'est arrogé le droit de traiter l'autre comme un objet" LÉVI-STRAUSS, Claude. Anthropologie structurale deux. Paris: Plon, 2006, p. 69.

103 Conforme ressalta Claude Rivière, "situado na história, o discurso antropológico não é inocente: numa determinada conjuntura colonial, ele é o discurso do explorador, do missionário, do administrador, do jurista, o que em nada afeta a competência e a perspicácia de alguns dentre eles." RIVIÈRE, Claude. Introdução à antropologia. Tradução de José Francisco Espadeiro Martins. Lisboa: Edições 70, 2004, p. 34-35. 


\section{Conclusão}

O presente artigo procurou analisar, em linhas gerais, o do pensamento de Henry James Sumner Maine, tal como se expressa no livro Ancient Law, considerado um clássico que estaria na base da formação tanto do campo da antropologia jurídica como do campo da sociologia jurídica. Trata-se de uma obra de grande envergadura que, entretanto, não deixa de se apresentar como historicamente comprometida pelos seus pressupostos evolucionistas que, ao manterem uma relação de "afinidade eletiva" com o imperialismo e o colonialismo, serão objeto de intensa crítica. Nesse sentido, enfatizouse que o presente artigo, embora procure evidenciar a relevância da obra de Maine, não corrobora ou aceita seus pressupostos. Trata-se antes de uma reconstrução pontual e assistemática que, articulada ao redor de apenas uma das obras do autor, pretendeu somente sublinhar a importância da mesma. Uma reconstrução mais consequente do pensamento de Maine demandaria uma análise que extrapola, inclusive no que concerne à necessidade de explicitação de seus pressupostos metodológicos, os limites deste artigo.

Deste modo, procurou-se indicar aspectos importantes do pensamento de Henry James Sumner Maine, sobretudo na forma em que este se expressa no clássico Ancient Law. A intenção de recuperar certos aspectos fundamentais do pensamento de Maine, com vistas a ressaltar sua importância histórica, se faz tanto mais importante se se considera que, no Brasil, mesmo após 150 anos da publicação de Ancient Law, tal obra continua a ser praticamente desconhecida. As raras alusões feitas por autores brasileiros à obra de Maine consistem, quando existentes, sobretudo, em simples referências pontuais. Portanto, mesmo quando a obra é referenciada, ela é raramente analisada e discutida. ${ }^{104}$ Ademais, mesmo as raras referências existentes acerca da obra de Maine têm progressivamente escasseado entre nós o que acarreta sua progressiva desconsideração, mesmo em análises que procuram fazer reconstruções históricas.

104 Dentre nossos autores clássicos, Miguel Reale, por exemplo, em sua obra Filosofia do direito, ao analisar as perspectivas que concebem o direito como "fato histórico", apenas menciona brevemente a Historical School of Jurisprudence de Maine. Alusões pontuais também aparecem em $O$ direito como experiência e em Horizontes do direito e da história. Cf. REALE, Miguel. Filosofia do direito. $20^{\mathrm{a}}$ edição. São Paulo: Saraiva, 2002, p. 426; . O direito como experiência. $2^{\mathrm{a}}$ edição. São Paulo: Saraiva, 1992, p. 151;

Horizontes do direito e da história. $3^{\mathrm{a}}$ edição. São Paulo: Saraiva, 2000, p. 303. Para uma apropriação um pouco mais aprofundada de Reale acerca do pensamento de Maine, sobretudo no que concerne à tese da evolução do status ao contrato, ver: REALE, Miguel. Teoria do direito e do Estado. $5^{\text {a }}$ edição. São Paulo: Saraiva, 2000, p. 179; 182; 187 e 241. Francisco José de Oliveira Vianna também alude brevemente à obra de Maine, articulando-a com as de Lévy-Bruhl e Durkheim. Cf. OLIVEIRA VIANNA, Francisco José de. Instituições politicas brasileiras. Belo Horizonte: Itatiaia; São Paulo: Editora da Universidade de São Paulo; Niterói, RJ: Editora da Universidade Federal Fluminense, 1987, v. 1, p. 42. 
Uma situação como essa é inaceitável, pois a obra de Maine, além de seu caráter pioneiro na análise histórico-comparativa do direito - que a alça a um patamar muito significativo no delineamento das abordagens antropológica e sociológica do direito, tal como as mesmas se constituíram no século XIX - apresenta também um enorme repositório de temáticas que são tradicionalmente enfocadas nas análises dos teóricos do direito. Nela encontram-se, por exemplo, uma importante expressão da reação do século XIX à doutrina do direito natural; uma discussão de caráter histórico sobre a questão da equidade; uma crítica às concepções de Austin e Bentham acerca do direito; uma abordagem histórica do instituto do contrato etc. Em meio à análise dessas temáticas, Maine discute, ademais, o pensamento de autores clássicos como Montesquieu, Grotius, Hobbes, Locke, Rousseau, Blackstone, Burlamaqui, entre outros, de modo que seu pensamento permite vislumbrar, ainda que parcialmente, o modo pelo qual tais clássicos foram recepcionados, na segunda metade do século XIX, por um autor importante no delineamento dos enfoques antropológico e sociológico acerca do direito.

São Paulo, agosto de 2011.

\section{Referências}

ANDRINI, Simona; ARNAUD, André-Jean. Jean Carbonnier, Renato Treves et la sociologie du droit: archéologie d'une discipline (entretiens et pièces). Paris: L.G.D.J, 1995.

ARNAUD, André-Jean. Critique de la raison juridique. 1. Où va la sociologie du droit? Paris: L.G.D.J., 1981.

. Pour une pensée juridique européenne. Paris: Presses Universitaires de France, 1991.

; FARIÑAS DULCE, María José. Introduction à l'analyse sociologique des systèmes juridiques. Bruxelles: Bruylant, 1998.

ASAD, Talal. Introduction. In: ASAD, Talal (Ed.). Anthropology \& the Colonial Encounter. 7. ed. New Jersey: Humanities Press: Atlantic Highlands, 1995, p. 9-19.

. Two European Images of Non-European Rule. In: ASAD, Talal (Ed.). Anthropology $\&$ the Colonial Encounter. 7. ed. New Jersey: Humanities Press: Atlantic Highlands, 1995. p. 103-118.

ASSIER-ANDRIEU, Louis. Diversité culturelle, diversité juridique: vues rétrospectives. In: CHAZEL, François; COMMAILLE, Jacques. (Dirs.) Normes juridiques et regulation sociale. Paris: L.G.D.J., 1991. p. 423-426. (Collection Droit et Société)

. L'anthropologie et la modernité du droit. Anthropologie et sociétés, v. 13, n. 1, p. 21 34, 1989. 
. Le juridique des anthropologues. Droit et société, v. 5, p. 91-110, 1987.

AUSTIN, John. The province of jurisprudence determined. Cambridge: Cambridge University Press, 2001.

BAECHLER, Jean. Un chef-d'œuvre d'Émile Durkheim: De la division du travail social. In: BOUDON, Raymond. Durkheim fut-il durkheimien? Actes du colloque organisé les 4 et 5 novembre 2008 par l'Académie des Sciences Morales et Politiques. Paris: Armand Colin, 2011, p. 11-25.

BERTHELOT, Jean-Michel. La construction de la sociologie. 6e édition. Paris: Presses Universitaires de France, 2006.

BOBBIO, Norberto. Thomas Hobbes. Tradução de Carlos Nélson Coutinho. Rio de Janeiro: Campus, 1991.

. O positivismo jurídico: lições de filosofia do direito. Tradução de e notas Márcio Pugliesi, Edson Bini e Carlos E. Rodrigues. São Paulo: Ícone, 1995.

CARBONNIER, Jean. Sociologie juridique. 2e édition. Paris: Presses Universitaires de France, 2008 .

COCKS, Raymond C. J. Sir Henry Maine: a Study in Victorian Jurisprudence. Cambridge: Cambridge University Press, 1988.

COPANS, Jean. Introduction à l'ethnologie et à l'anthropologie. 3é éd. Paris: Armand Colin, 2010.

Da etnologia à antropologia. In: COPANS, Jean; TORNAY, Serge; GODELIER, Maurice; BACKÈS-CLÉMENT, Catherine. Antropologia: ciência das sociedades primitivas? Tradução de J. Pinto de Andrade. Lisboa: Edições 70, 1988. p. 13-41.

DA MATTA, Roberto. Repensando E. R. Leach. In: DA MATTA, Roberto (Org.). Edmund Ronald Leach: antropologia. Tradução de Alba Zaluar Guimarães. São Paulo: Ática, 1983. p. 7-54. (Col. Grandes Cientistas Sociais)

DELIÈGE, Robert. Anthropologie sociale et culturelle. 2e. édition. Bruxelles: De BoeckWesmael, 1995.

. Une histoire de l'anthropologie. Écoles, auteurs, théories. Paris: Éditions du Seuil, 2006.

DESCOLA, Philippe. Claude Lévi-Strauss, une présentation. In: La Lettre du Collège de France, hors de série n. 2: Claude Lévi-Strauss, centième anniversaire. Paris: Collège de France, 2008. p. 4-8.

DIAMOND, Alan (Ed.). The Victorian Achievement of Sir Henry Maine: a Centennial Reappraisal. New York: Cambridge University Press, 1991. 
DURKHEIM, Émile. De la division du travail social. 7e édition. Paris: Presses Universitaires de France, 2007.

DURKHEIM, Émile. Leçons de sociologie. 5e édition. Paris: Presses Universitaires de France, 2010 .

EVANS-PRITCHARD, Edward Evan. Antropologia social. Tradução de Ana Maria Bessa. Lisboa: Edições 70, 1999.

FARIA, José Eduardo; CAMPILONGO, Celso Fernandes. A sociologia jurídica no Brasil. Porto Alegre: Sergio Antonio Fabris Editor, 1991.

FERRAZ JUNIOR, Tercio Sampaio. Estudos e filosofia do direito: reflexões sobre o poder, a liberdade, a justiça e o direito. $3^{\text {a }}$ ed. São Paulo: Atlas, 2009.

GLUCKMAN, Max. Obrigação e dívida. In: DAVIS, Shelton H. Antropologia do direito: estudo comparativo de categorias de dívida e contrato. Tradução de Vera Maria Cândido Pereira. Rio de Janeiro: Zahar, 1973.

GODELIER, Maurice. Au fondement des sociétés humaines: ce que nous apprend l'anthropologie. Paris: Albin Michel, 2007.

. Communauté, société, culture: trois clefs pour comprendre les identités en conflits. Paris: CNRS Éditions, 2009.

. Les tribus dans l'histoire et face aux États. Paris: CNRS Éditions, 2010.

GRZEGORCZYK, Christophe; MICHAUT, Françoise; TROPER, Michel. Le positivisme juridique. Paris: L.G.D.J, 1992.

GUINCHARD, Jean-Jacques. Max Weber: vie, oeuvres, concepts. Paris: Éditions Ellipses, 2006.

HART, Herbert Lionel Adolphus. O conceito de direito. Tradução de Armindo Ribeiro Mendes. Lisboa: Fundação Calouste Gulbenkian, 1986.

HOEBEL, Edward Adamson. The law of primitive man: a study in comparative legal dynamics. Cambridge, Massachusetts: Harvard University Press, 2006.

HÖFFE, Otfried. Justiça política: fundamentação e uma filosofia crítica do direito e do Estado. Tradução de Ernildo Stein. Petrópolis, RJ: Vozes, 1991.

JAMES, Wendy. The Anthropologist as Reluctant ilmperialist. In: ASAD, Talal. (Ed.) Anthropology \& the Colonial Encounter. 7. ed. New Jersey: Humanities Press: Atlantic Highlands, 1995. p. 41-69.

KANT DE LIMA, Roberto. Ensaios de antropologia e de direito: acesso à justiça e processos institucionais de administração de conflitos e produção da verdade em uma perspectiva comparada. Rio de Janeiro: Lumen Juris, 2008. 
KELLY, John Maurice. Uma breve história da teoria do direito ocidental. Tradução de Marylene Pinto Michael. São Paulo: Martins Fontes, 2010.

KOSELLECK, Reinhart. Vergangene Zukunft. Zur Semantik geschichtlicher Zeiten. Frankfurt am Main: Suhrkamp, 1989. (trad. brasileira: Futuro Passado: contribuição à semântica dos tempos históricos. Tradução de Wilma Patrícia Maas e Carlos Alberto Pereira. Rio de Janeiro: Contraponto; Editora PUC-Rio, 2006).

KROTZ, Esteban. Sociedades, conflictos, cultura y derecho desde uma perspectiva antropológica. In: KROTZ, Esteban. (Ed.) Antropología jurídica: perspectivas socioculturales en el estudio del derecho. Rubí (Barcelona): Anthropos Editorial; México: Universidad Autónoma Metropolitana - Iztapalapa, 2002, p. 13-49.

LAFER, Celso. Hobbes, o direito e o Estado moderno. São Paulo: Associação dos Advogados de São Paulo, 1980.

LEACH, Edmund R. The epistemological background to Malinowski empiricism. FIRTH, Raymond (ed.). Man and culture: an evaluation of the work of Bronislaw Malinowski. London: Routledge \& Kegan Paul, 1957, p. 119-137.

L'ESTOILE, Benoît de; NEIBURG, Federico; SIGAUD, Lygia. Antropologia, impérios e Estados nacionais: uma abordagem comparativa. In: L'ESTOILE, Benoît de; NEIBURG, Federico; SIGAUD, Lygia. (Orgs.). Antropologia, impérios e estados nacionais. Tradução de Marcela Coelho de Souza. Rio de Janeiro: Relume Dumará: FAPERJ, 2002. p. 9-37.

L'ESTOILE, Benoît de. Ciência do homem e “dominação racional”: saber etnológico e política indígena na África colonial francesa. In: L'ESTOILE, Benoît de; NEIBURG, Federico; SIGAUD, Lygia. (Orgs.) Antropologia, impérios e estados nacionais. Rio de Janeiro: Relume Dumará, 2000, p. 61-93.

LÉVI-STRAUSS, Claude. Anthropologie structurale deux. Paris: Plon, 2006. . Race et histoire. Paris: Denoël, 1987.

LUHMANN, Niklas. Ausdifferenzierung des Rechts. Beiträge zur Rechtssoziologie und Rechtstheorie. Frankfurt am Main: Suhrkamp, 1999.

. Das Recht der Gesellschaft. Frankfurt am Main: Suhrkamp, 1993. (Trad. inglesa: Law as a social system. Oxford: Oxford University Press, 2004; trad. espanhola: El derecho de la sociedad. México: Universidad Iberoamericana, 2002).

. Rechtssoziologie. 4. Aufl. Wiesbaden: VS Verlag für Sozialwissenschaften, 2008.

MACCORMICK, Neil. H. L. A. Hart. Tradução de Cláudia Santana Martins. Rio de Janeiro: Elsevier, 2010.

MACPHERSON, Crawford Brough. The political theory of possessive individualism: Hobbes to Locke. Don Mills, Ont.; Oxford: Oxford University Press Canada, 2011. 
MAINE, Henry James Sumner. Ancient Law, its Connection with the Early History of Society, and its Relation to Modern Ideas. Tucson, Arizona: The University of Arizona Press, 1986.

. Lectures on the Early History of Institutions. $6^{\text {th }}$ ed. London: John Murray, 1898.

MALINOWSKI, Bronislaw. Crime and Custom in Savage Society. $7^{\text {th }}$ Ed. London: Routledge \& Kegan Paul Ltd., 1961.

MILLARD, Éric. Théorie générale du droit. Paris: Dalloz, 2006.

MOORE, Sally Falk. Certainties undone: fifty turbulent years of legal anthropology, 19491999. The Journal of the Royal Anthropological Institute, v. 7, n. 1, p. 95-116, march 2001.

. Sally. Law and Anthropology: a reader. Malden/USA: Blackwell, 2005.

MORGAN, Lewis Henry. Ancient society, or researches in the lines of human progress form savagery throught barbarism to civilization. New Brunswick, New Jersey: Transaction Publishers, 2000.

NICOLAU, Gilda; PIGNARRE, Geneviève; LAFARGUE, Régis. Ethnologie juridique: autour de trois exercices. Paris: Dalloz, 2007.

OLIVEIRA VIANNA, Francisco José de. Instituições politicas brasileiras. Belo Horizonte: Itatiaia; São Paulo: Editora da Universidade de São Paulo; Niterói, RJ: Editora da Universidade Federal Fluminense, 1987. v. 1.

OPPETIT, Bruno. Philosophie du droit. Paris: Dalloz, 1999.

ORENSTEIN, Henry. The ethnological theories of Henry Sumner Maine. American Anthropologist, 70, p. 264-276, 1968.

OST, François; KERCHOVE, Michel van de. De la scène au balcon. D'où vient la science du droit?. In: CHAZEL, François; COMMAILLE, Jacques. (Dirs.) Normes juridiques et regulation sociale. Paris: L.G.D.J., 1991, p. 67-80. (Collection Droit et Société)

PAPILlOUD, Christian. Simmel, Durkheim et Mauss. Naissance ratée de la sociologie européenne. In: Revue du MAUSS, 2000/2 (n. 20), p. 300-327.

PARSONS, Talcott. The structure of social action. A study in social theory with special reference to a group of recent european writers. New York: The Free Press, 1968.

PEÑA, Guillermo de la. Costumbre, ley y procesos judiciales en la antropología clásica: apuntes introductorios. In: KROTZ, Esteban. (Ed.) Antropología juridica: perspectivas socioculturales en el estudio del derecho. Rubí (Barcelona): Anthropos Editorial; México: Universidad Autónoma Metropolitana - Iztapalapa, 2002. p. 51-68.

POLLOCK, Frederick. Introduction and notes to Sir Henry Sumner Maine's "Ancient Law". London: John Murray, 1914. 
PÖLÖNEN, Janne. The case for a Sociology of Roman Law. In: FREEMAN, Michael (Ed.). Law and sociology: current legal issues vol. 8. Oxford: Oxford University Press, 2005, p. 398408.

RADCLIFFE-BROWN, Alfred Reginald. Structure and Function in Primitive Society. London: Cohen \& West Ltd., 1952.

. The comparative method in social anthropology. In: KUPER, Adam (Ed.). The social anthropology of Radcliffe-Brown. London: Routledge \& Kegan Paul Ltd., 1977. p. 53-68.

REALE, Miguel. Filosofia do direito. 20. ed. São Paulo: Saraiva, 2002.

. Horizontes do direito e da história. 3. ed. São Paulo: Saraiva, 2000.

. O direito como experiência. 2. ed. São Paulo: Saraiva, 1992.

. Teoria do direito e do Estado. 5. ed. São Paulo: Saraiva, 2000.

RIBEIRO, Darcy. O processo civilizatório: etapas da evolução sociocultural. São Paulo: Companhia das Letras; Publifolha, 2000. ( Grandes nomes do pensamento brasileiro)

RIBEIRO, Renato Janine. Ao leitor sem medo: Hobbes escrevendo contra o seu tempo. Belo Horizonte: Editora da UFMG, 1999.

RIVIÈRE, Claude. Introdução à antropologia. Tradução de José Francisco Espadeiro Martins. Lisboa: Edições 70, 2004.

ROULAND, Norbert. Anthropologie juridique. Paris: Presses Universitaires de France, 1988. L'Anthropologie Juridique. 2e. ed. Paris: Presses Universitaires de France, 1995. (Que Sais-je?, 2528).

. Nos confins do direito. Tradução de Maria Ermantina de Almeida Prado Galvão. São Paulo: Martins Fontes, 2003.

RUDE-ANTOINE, Edwige; CHRÉTIEN-VERNICOS, Geneviève. Parenté, famille, mariage, filiation. In: RUDE-ANTOINE, Edwige; CHRÉTIEN-VERNICOS, Geneviève (Coord.). Anthropologies et droits: état des savoirs et orientations contemporaines. Paris: Dalloz, 2009. p. 271-313.

SACCO, Rodolfo. Anthropologie juridique: apport à une macro-histoire du droit. Paris: Dalloz, 2008.

SÈVE, René. Philosophie et théorie du droit. Paris: Dalloz, 2007.

SERVERIN, Évelyne. Sociologie du droit. Paris: La Découverte, 2000.

SGARBI, Adrian. Clássicos da teoria do direito. 2. ed. Rio de Janeiro: Lumen Juris, 2009. 
SHILS, Edward. Henry Sumner Maine in the tradition of the analysis of society. In: DIAMOND, Alan (Ed.). The Victorian achievement of Sir Henry Maine: a centennial reappraisal. New York: Cambridge University Press, 1991. p. 143-178.

SHIRLEY, Robert Weaver. Antropologia jurídica. São Paulo: Saraiva, 1987.

SPERBER, Dan. O saber dos antropólogos: três ensaios. Tradução de José Martha Aragão. Lisboa: Edições 70, 1992.

SUPIOT, Alain. Homo juridicus. Essai sur la fonction anthropologique du droit. Paris: Éditions du Seuil, 2005.

SWEDBERG, Richard. The Max Weber dictionary: key words and central concepts. Stanford: Stanford University Press, 2005.

TAROT, Camille. Sociologie et anthropologie de Marcel Mauss. Paris: La Découverte, 2003.

TODOROV, Tzvetan. Nous et les autres: la réflexion française sur la diversité humaine. Paris: Éditions du Seuil, 1989.

TÖNNIES, Ferdinand. Communauté et société. In: DANIEL, Jean (Dir.) La société: les plus grands texts d'Auguste Comte et Émile Durkheim à Claude Lévi-Strauss. Paris: Le Nouvel Observateur/CNRS Éditions, 2011. p. 131-219.

TREVES, Renato. Sociologia do direito: origens, pesquisas e problemas. Tradução de Marcelo Branchini. Barueri,SP: Manole, 2004.

TREVIÑO, A. Javier. The sociology of law: classical and contemporary perspectives. New Jersey: Transaction Publishers, 2008.

TROPER, Michel. Le droit et la nécessité. Paris: Presses Universitaires de France, 2011.

TUCK, Richard. Natural Rights Theories: their origin and development. Cambridge: Cambridge University Press, 1995.

VANDERLINDEN, Jacques. Anthropologie juridique. Paris: Dalloz, 1996.

VILLAS BÔAS FILHO, Orlando. A constituição do campo de análise e de pesquisa da antropologia jurídica. In: Prisma Jurídico. São Paulo, v. 6, p. 333-349, 2007.

A sociologia do direito: o contraste entre a obra de Émile Durkheim e a de Niklas Luhmann. In: Revista da Faculdade de Direito da USP, v. 105, p. 561-593, jan./dez. 2010.

VILLEY, Michel. A formação do pensamento jurídico moderno. Tradução de Cláudia Berliner. São Paulo: Martins Fontes, 2009.

WEINREB, Lloyd L. Natural Law and Justice. Cambridge, Massachusetts: Harvard University Press, 1987. 
WOODMAN, Gordon R. The involvement of English Common Law with other Laws. In: EBERHARD, Christoph; VERNICOS, Geneviève (Eds.). La quête anthropologique du droit: autour de la demarche d'Étienne le Roy. Paris: Karthala, 2006, p. 477-500.

ZAGORIN, Perez. Hobbes and the Law of Nature. Princeton, New Jersey: Princeton University Press, 2009. 